\title{
Design, simulation and manufacturing of a connecting rod from ultra-fine grained material and isothermal forging
}

\author{
J.P. Fuertes, C.J. Luis, R. Luri, D. Salcedo, J. León and I. Puertas \\ Mechanical, Energetics and Materials Engineering Department \\ Public University of Navarre \\ Campus de Arrosadía, s/n \\ 31006 Pamplona (Spain) \\ E-mail: inaki.puerta@unavarra.es
}

\begin{abstract}
Mr. Juan Pablo Fuertes is an Assistant Professor and he belongs to the Materials and Manufacturing Engineering Research Group from the Public University of Navarre (Spain). He is developing his Doctoral Thesis in the field of severe plastic deformation processes under the supervision of Dr. C.J. Luis and Dr. R. Luri.
\end{abstract}

E-mail: juanpablo.fuertes@unavarra.es

Dr. Carmelo Javier Luis is a Full Professor and Leader of the Materials and Manufacturing Engineering Research Group from the Public University of Navarre (Spain). His current research focuses on EDM and severe plastic deformation processes.

E-mail: cluis.perez@unavarra.es

Dr. Rodrigo Luri is an Associate Professor and he belongs to the Materials and Manufacturing Engineering Research Group from the Public University of Navarre (Spain). His current research focuses on severe plastic deformation processes.

E-mail: rodrigo.luri@unavarra.es

Dr. Daniel Salcedo is an Assistant Professor and he belongs to the Materials and Manufacturing Engineering Research Group from the Public University of Navarre (Spain). His current research focuses on severe plastic deformation processes.

E-mail: daniel.salcedo@unavarra.es

Dr. Javier León is an Associate Professor and he belongs to the Materials and Manufacturing Engineering Research Group from the Public University of Navarre (Spain). His current research focuses on severe plastic deformation processes.

E-mail: javier.leon@unavarra.es

Dr. Ignacio Puertas is an Associate Professor and he belongs to the Materials and Manufacturing Engineering Research Group from the Public University of Navarre (Spain). His current research focuses on EDM and severe plastic deformation processes.

E-mail: inaki.puerta@unavarra.es

\section{ABSTRACT}

In this research work, a study on the mechanical properties of isothermal forging for connecting rods is made from previously ECAP (Equal Channel Angular Pressing)processed AA1050 and AA5083 aluminium alloys. This severe plastic deformation (SPD) process is used in order to achieve a starting material with a submicrometric structure, thus improving the mechanical properties of the part. In this study, the design and the experimentation process is shown, where this involves the design stage by finite element simulations, the experimental tests and the use of metallographic techniques for the required properties to be analysed. It is observed that there is an improvement in the mechanical properties when the starting material is ECAPprocessed before carrying out the isothermal forging. This improvement consists in an 
increase of $20 \%$ in the hardness of the final connecting rod which also possesses a microstructure grain size of $500 \mathrm{~nm}$. To come to these conclusions, the results obtained with the connecting rods manufactured by isothermal forging from previously ECAP-processed material are compared with those conventionally manufactured. Therefore, the feasibility and the advantages of the industrial manufacturing of mechanical components by isothermal forging from ECAP-processed material are demonstrated here as mechanical properties are achieved, as well as a better flow of the material and at a lower forging temperature. In the existing bibliography, there are no research works dealing with the manufacturing of connecting rods from ultra-fine grained material and that is the reason why this present study is considered to be of scientific and technological interest, and therefore, it may be considered to be at the frontline of current knowledge.

Keywords: Isothermal Forging, FEM, ECAP, SPD

\section{Introduction}

The Equal Channel Angular Pressing (ECAP) process was first proposed by Segal et al. [1] in 1972 in the former Soviet Union in order to obtain ultra-fine grained materials by severe plastic deformation (SPD). Nevertheless, it is over these past few years when a great deal of scientific and technological interest has come about from the development and application of these materials. It consists in a discontinuous severe plastic deformation process in which a material is extruded through a die with two channels of the same cross-section that intersect at an angle between $80^{\circ}$ and $135^{\circ}$. The material may be processed several times in order to accumulate a higher plastic strain value inside it [2]. In comparison with other severe plastic deformation processes, this process is the one which introduces the most homogeneous strain values and allows parts with higher size to be processed [3]. Over the last decade, the ECAP process has become a manufacturing process of ultrafine grain size metals and alloys used to improve their mechanical properties. In spite of the great interest in these materials, few elaborations exist that attempt to exploit these above-mentioned advantages.

Although the number of research works which analyse the ECAP properties over the materials thus-processed is numerous, the number of practical applications of these materials is scant. As examples of manufactured parts, it is interesting to mention the research work by Luis et al. [4], in which the design and subsequent manufacturing of rings are carried out from ECAP ultra-fine grained material. The manufacturing of these is designed by means of finite element simulations with two forging strokes or stages and both the mechanical properties and the microstructure are studied. A comparison is made between the results obtained at different forging temperatures [4]. Puertas et al. [5] study the design of a Francis turbine blade from ECAP-processed AA1050 and 
then subjected to isothermal forging. It is observed that there is a noticeable improvement in the mechanical properties as a consequence of the submicrometric structure gained by ECAP and which allows parts with better mechanical properties to be manufactured from ultra-fine grained material.

In the existing bibliography, several research works related to the design, analysis and manufacturing of connecting rods are found. Nevertheless, none of them is related to the manufacturing of this mechanical component from ultra-fine grained material, as has been proposed as an innovation in this present research work.

Finite element studies have been improved more and more with the passing of the years. In the one by Takemasu et al. [6], the objective is to design the forging process of a connecting rod with no flash in order to save costs. To this end, it is necessary to finely control the volume and geometry of the preform in order to avoid both the flash appearance and the incomplete die filling. The optimization of this process is carried out by finite element simulations and the authors divide the preform into three different parts which are separately simulated. As a further advancement to this research work, Vazquez and Altan [7] make a design for hot forging of connecting rods by finite element with the aim of saving material costs as the amount of flash is reduced. They also make a comparison between these results and other results experimentally obtained. The die and preform design is iterative in order to reach a part with no flash which is the best adjusted to the final geometry. The results obtained achieve a flash saving of between $20 \%$ to $40 \%$, in relation to conventional forging, where the final flash percentage is $5 \%$ with respect to the part.

As is the case for this present study, most of the existing research works use the finite element analysis as a tool for the forging design. There are research works such as that by Grass et al. [8] in which the thermo-mechanical manufacturing process of a connecting rod is analysed by FEM, where it is composed of several rolling and forging stages. In this study, it is observed that the precision of the FEM simulations is very high if it is compared to the experimental tests. Moreover, it is seen that it is possible to study the material flow by following several points throughout the simulation. In another FEM study by Grass et al. [9], these authors study not only the temperature influence on the strain introduced in the material but also the grain size prediction during the forming process at temperature with the help of recrystallization models defined. The results are very similar in comparison to those experimentally obtained.

There are other studies in which finite element method is used in order to evaluate the viability of other methods for manufacturing parts [10]. Furthermore, it is very important to accurately predict springback when working with sheet metal [11]. In the research by Yin et al. [12], these authors study the forging process of an aluminium connecting rod 
for an air compressor. They substitute the manufacturing process by casting or hot forging for a liquid die forging, thus avoiding the appearance of defects produced by pores or non-metallic inclusions. Thanks to this manufacturing process, the product quality is improved and it is observed that this plastic forming technique is very useful. The research work by Wang and He [13] reviews the developments that have been applied to the manufacturing of connecting rods. These are based on the addition of a central feeding system for the billet and a temperature control system, the use of 3D CAD/CAM tools so as to optimise the rolling and transversal rolling processes, the improvement in accuracy thanks to better equipment such as hydraulic presses and transversal rolling machinery and an improvement in quality due to the use of dies which allows trimming, punching and calibrating operations to be combined. Along this line, it is also very important to model and to simulate the shaping/forming machinery and equipment, above all in relation to its dynamic behaviour [14]. There also exist studies related to the forging of connecting rods from dust material such as the one by Qiu et al. [15]. The starting material is metallic dust from a Ti-1.5Fe-2.25Mo (wt. \%) alloy and FEM simulations are employed to analyse the process. It is observed that the mechanical strength at the end of the piston rivet of the part is the lowest, whereas it is homogeneous for the rest.

The use of finite element modelling is not only related to the process design but to the study of the material behaviour as is the case of the research work by Chen et al. [16], in which the mechanical properties of a connecting rod are intended to be improved by a modification to the manufacturing process which consists in changing the liquid used for quenching the part. Oil is changed into aqueous polymer or water. These authors compare the results obtained from the connecting rods quenched in the new fluid with the original ones and it is observed that that the mechanical properties are better and no cracks appear. Finite element analysis is used so as to simulate the quenching process and it is found that there is a good correlation between the results simulated and those experimentally obtained. Another study on the behaviour of a material is that by Khare et al. [17], where the causes for the cracks that occur are studied by finite element simulations in the case of the connecting rods for a gasoline engine. Once the critical zones of the part are analysed, a redesign is made in order to avoid the connecting rod failure to fatigue. This new redesign is also analysed by finite element and it is experimentally validated in order to check the reliability of the FEM simulations, which are in good agreement with experimental results.

In a preliminary research to this present study, Luri et al. [18] shows the design process of a set of forging dies to manufacture a connecting rod from ultra-fine grained material. 
The forging process is designed with two strokes and is simulated both by finite volume and finite element modelling in the case of an AA5083 aluminium alloy.

As was previously mentioned, in this present study connecting rods are manufactured from nanostructured starting material. In order to achieve this submicrometric structure, the material is previously ECAP-processed.

In the existing bibliography, there are numerous and different studies on the ECAP process, depending on the type of metal or alloy employed. Some of these research works are outlined below, where they are focused on the parameters which influence the mechanical properties and on the microstructure of the material, such as the number of passages, the ECAP route employed and the intersection angle.

In relation to the ECAP processing, there are several research studies in which compression tests are performed in order to add a new variable for improvement in the mechanical properties.

Another of the important parameters to be analysed is the number of ECAP passages the billet is subjected to. In the study by Alhajeri et al. [19], AA1050 billets are ECAPprocessed at room temperature up to six passages in order to analyse the mechanical properties of the material by means of taking microhardness measurements along the longitudinal and transversal axes. It is observed that after the first ECAP passage, the increase in strain is the highest in relation to the others. The highest strain value is located at the centre after the first passage but when the number of ECAP passages is increased, the strain distribution becomes more homogeneous.

One of the most important aspects to be taken into consideration in relation to the microstructure of ECAP-processed materials is the heat treatment that these materials are subjected to. In the research work by Luis et al. [20], an improvement both in the mechanical properties and in the grain size is observed in the case of a previously ECAP-processed AA1050 which is subjected to a subsequent heat treatment. These authors applied a heat treatment at $300^{\circ} \mathrm{C}$ during $5 \mathrm{~h}$ which produces recrystallization and thus leads to a significant improvement in the ductility of the material processed in relation to the starting material.

\section{Optimization of the die design}

This section deals with the way the design of the isothermal forging for the connecting rod is carried out. A great deal of research has been carried out over the past few years in the field of engineering design, thus leading to different design processes and methodologies [21]. In addition, it is very interesting to utilise complementary design tools at an early stage of the design process, such as the finite element method [22]. 
In order to manufacture the part by isothermal forging, a previous design of both the starting billet and the forging dies needs to be carried out in order to be capable of knowing in advance if the forging is correctly performed and within the hydraulic press capacity used in this study, which is $3000 \mathrm{kN}$.

To obtain an optimum design (see Figure 1), it is necessary to carry out a process which involves several iterations. A first design of the die and the starting billet is taken as the basis. Subsequently, finite volume simulations with the Simufact Forming $12^{\mathrm{TM}}$ software are performed in order to analyse the processing force, the flow of the material and the correct filling of the die. If any of these factors is deficient, a new design for the initial billet is made either by increasing the material volume in those zones where the cavity is not properly filled or decreasing the material volume if the flash is excessive, which causes a significant increase in the processing force. It should be taken into account that the starting billet has fixed maximum dimensions with a diameter of $18 \mathrm{~mm}$ and a length of $80 \mathrm{~mm}$. Therefore, the dimensions of the connecting rod have to be in line with the available material volume due to the limitations of the ECAP press in use at the Public University of Navarre. After several redesigns with which the forging process is refined, the final part is obtained fulfilling the established requirements.

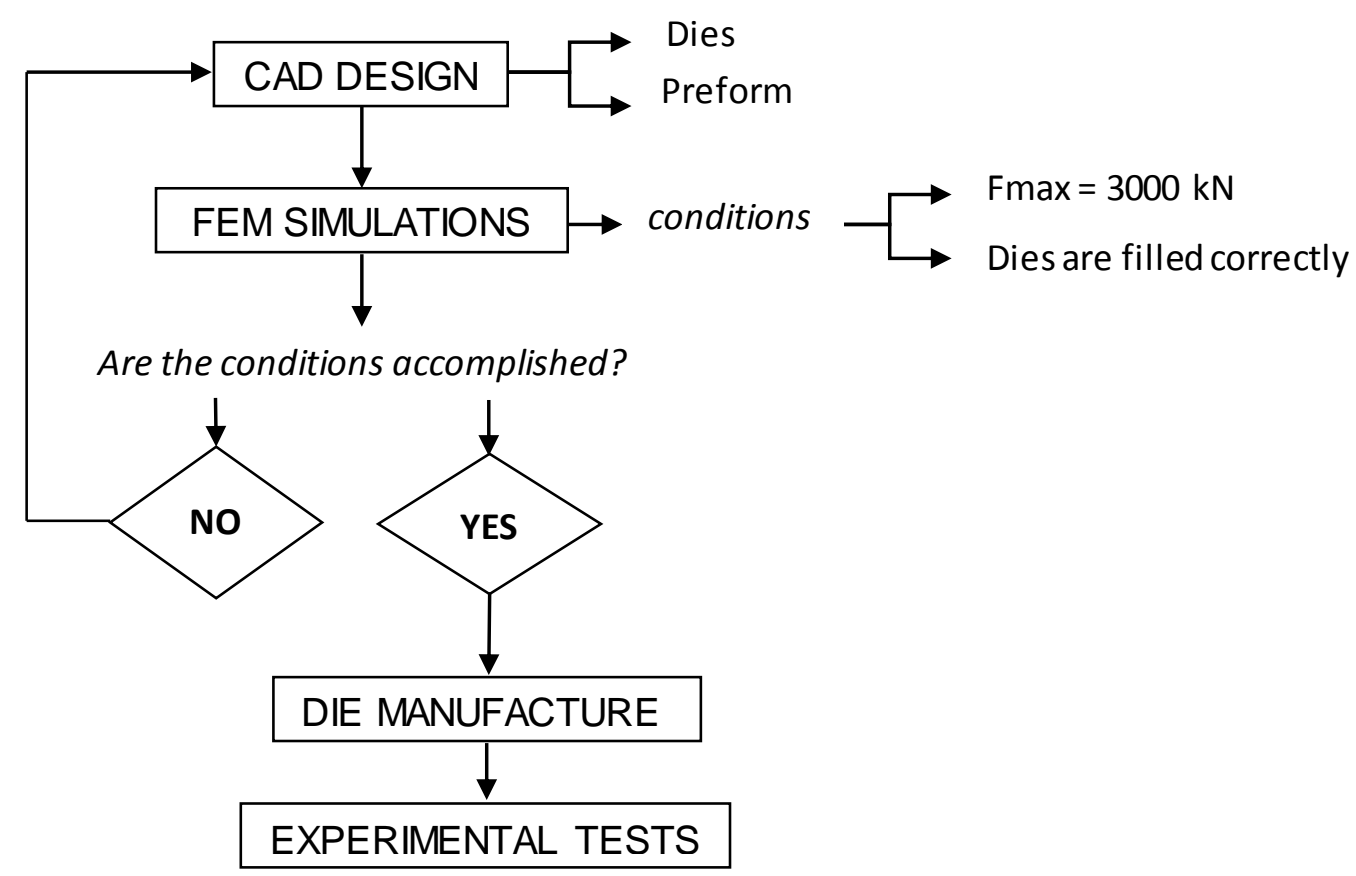

Figure 1. Flow diagram for the optimization process

Figures 2 (a) to 2 (h) show different cases in which the requirements established for a correct design of both the die and the starting billet are not fulfilled. 


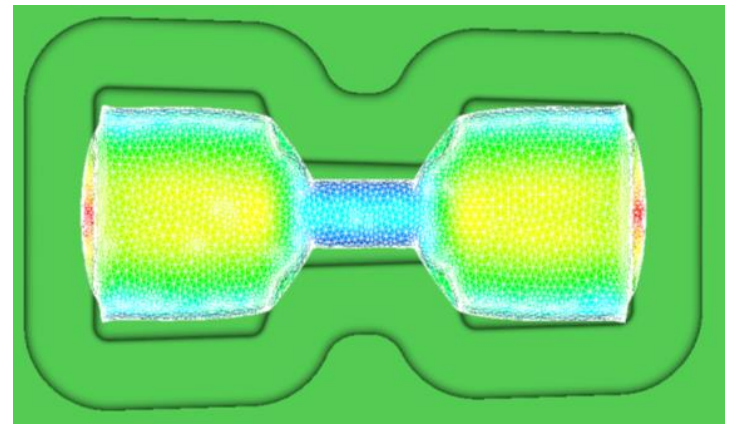

a) Unfilled preform die

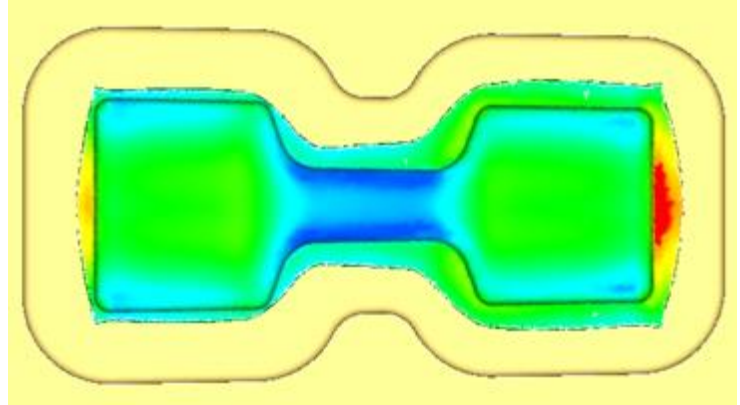

c) Overfilled preform die

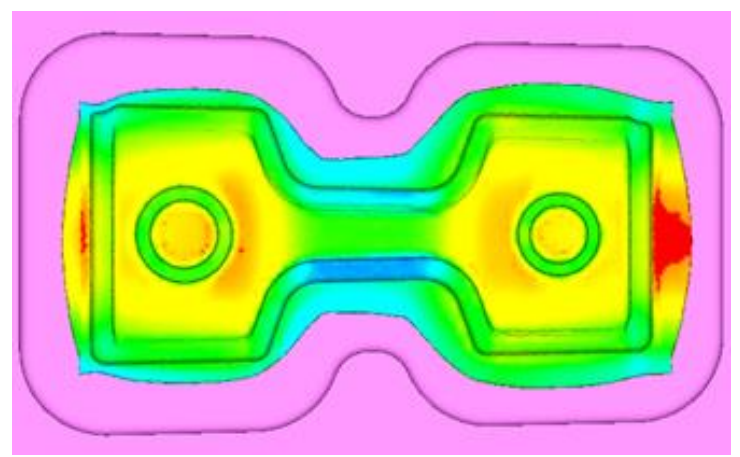

e) Unfilled final die

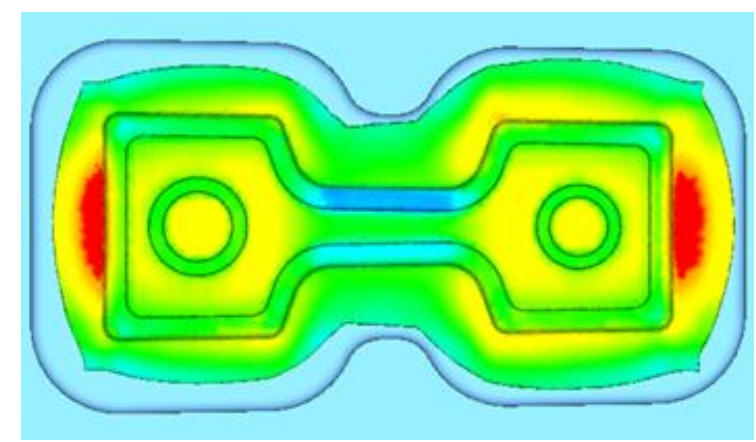

g) Overfilled final die

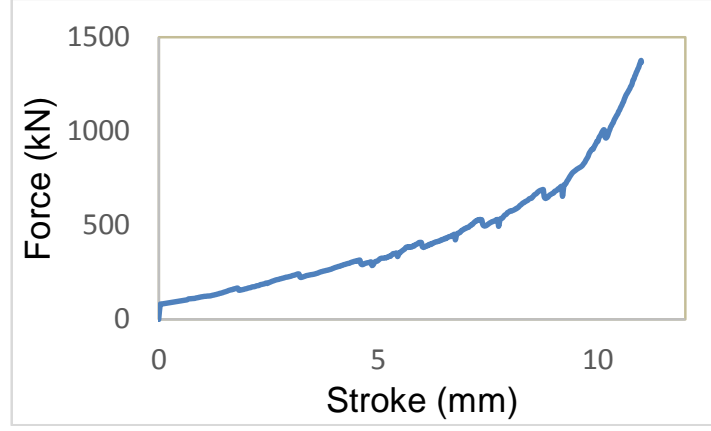

b) Stroke-load curve for an unfilled preform die

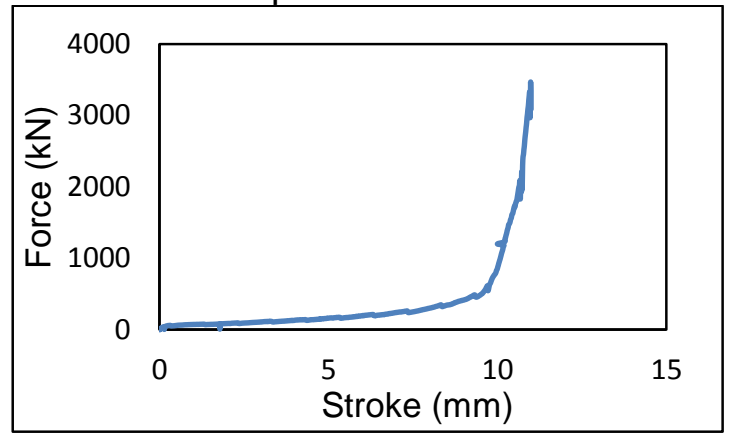

d) Stroke-load curve for a overfilled preform die

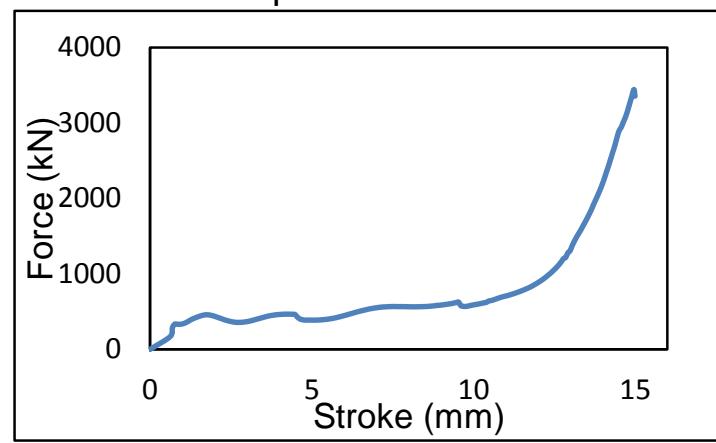

f) Stroke-load curve for an unfilled final die

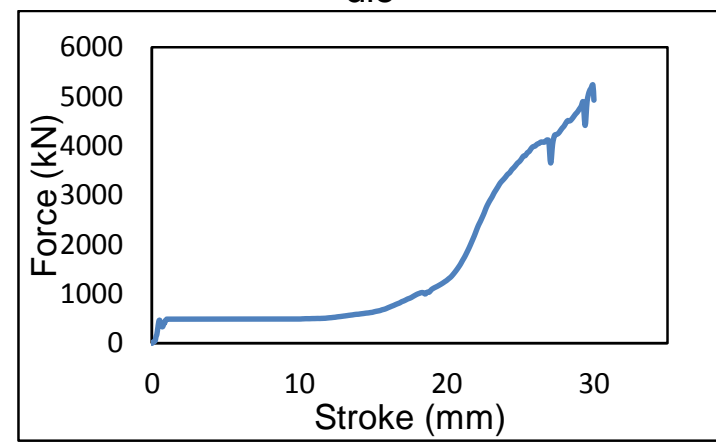

h) Stroke-load curve for an overfilled final die

Figure 2. Different failures in FEM models

If the designs corresponding to the preform forging are analysed, it may be observed in Figure 2 (a) that the die filling is not sufficient. As one of the two conditions established for the correct die design (Figure 1) is not fulfilled, the dimensions of both the preform and the forging die are redesigned. Figure 2 (b) shows the load-stroke curve of the 
process, where it is observed that the forging force has a value within the capacity of the hydraulic press. Figure 2 (c) shows the complete filling of the die but nevertheless, when Figure 2 (d) is analysed, it is observed that the force required exceeds the limit of $3000 \mathrm{kN}$ for the hydraulic press and therefore, it is necessary to make a new redesign. Once the optimum design is achieved, the second forging stroke, with which the final connecting rod is manufactured, starts to be analysed.

Figure 2 (e) shows an example of simulation where the die cavity is not completely filled. This case does not fulfil the second requirement either, as the maximum press force is exceeded, as can be observed in Figure 2 ( $f$ ). Therefore, a new redesign of the final forging die is needed. Figure 2 (g) shows a complete die filling but however, the amount of flash required is too high. This leads to an increase in the force required to carry out the second stroke, which can be observed in Figure $2(\mathrm{~h})$, where it is shown that the force required for this final stroke is higher than $5000 \mathrm{kN}$.

After several iterations for the design process, the adequate preform and forging dies are obtained in order to carry out the experimental tests (see Figure 3).

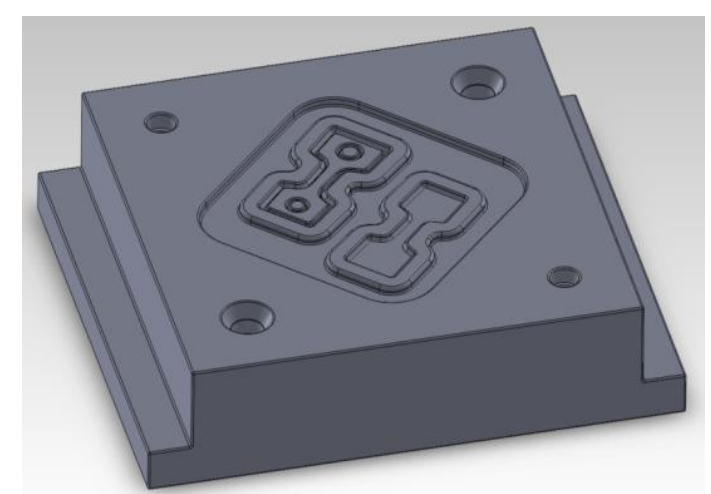

a) Final design for the bottom die

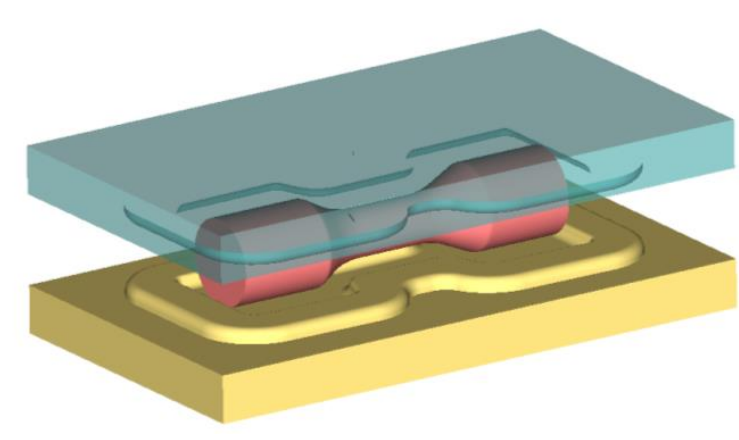

b) Set of the dies with the preform

Figure 3. Design of the dies from finite elements analysis

The meshing of both the die and the preform is automatically performed. Initially, nearly 11000 elements are used for the first forging stroke (see Figure 4 (a)) and nearly 40000 elements for the second forging stroke (see Figure 4 (b)). The elements used here are tetrahedral with four integration points and an edge size of $1 \mathrm{~mm}$.

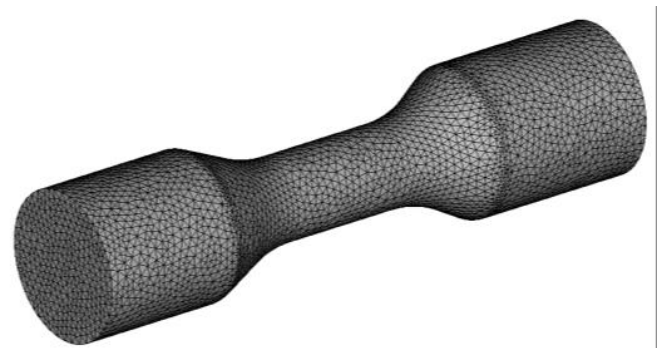

a) Initial billet mesh

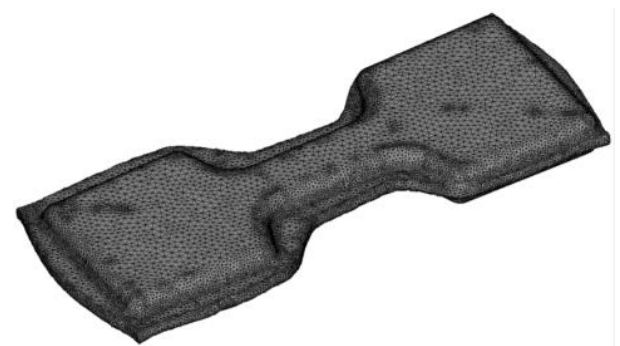

b) Preform mesh 
Figure 4. Finite element meshing of the initial billet and the preform

Finite volume simulations are carried out with a flow rule for AA5083 nanostructured after two ECAP passages [23]. In this case, there is no problem in performing the isothermal forging as the equipment for the experimental tests to be carried out allows a maximum force of $3000 \mathrm{kN}$.

In order to be able to obtain the damage results for the material, the Cockroft-Latham's damage criterion has been selected. Once the pre-processing steps have been shown, the results obtained in the case of the strain and the damage values are shown for each of the two forging strokes.

In the case of the first stroke (see Figure 5), a connecting rod preform is obtained and subsequently, this is subjected to a second stroke so as to achieve the final shape. The processing force, the plastic strain and the damage value are studied, where Figure 5 shows the strain and damage results after the first stroke.

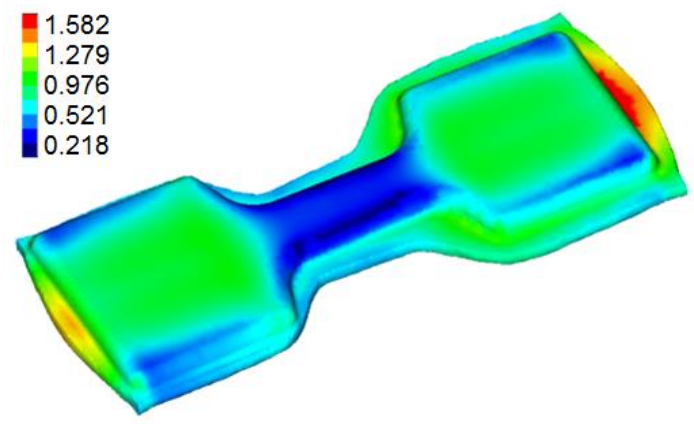

a) Total equivalent plastic strain

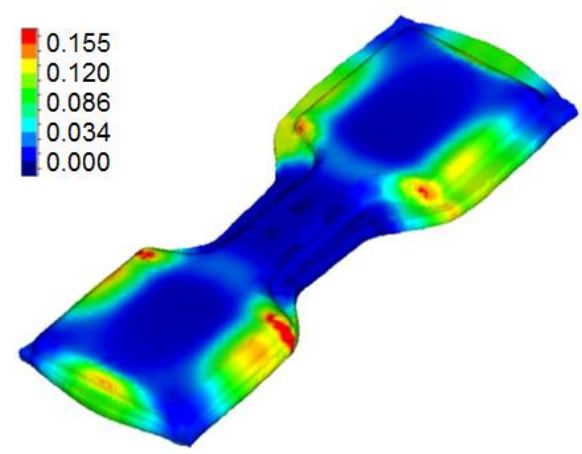

b) Damage

Figure 5. Total equivalent plastic strain and damage results

It may be observed from the strain results shown in Figure 5 (a) that the distribution is rather homogeneous throughout the part, where the central part is that with the lowest strain value. Figure 5 (b) shows the zones with the highest damage values, which are the internal edges of the two heads, whereas the zone with the lowest damage value is the internal one.

In the second stroke shown in Figure 6, the final shape is obtained for the one-piece connecting rod. Taking the strain value accumulated by the preform in the first stroke into account, the results for the plastic strain are shown in this previous figure. 


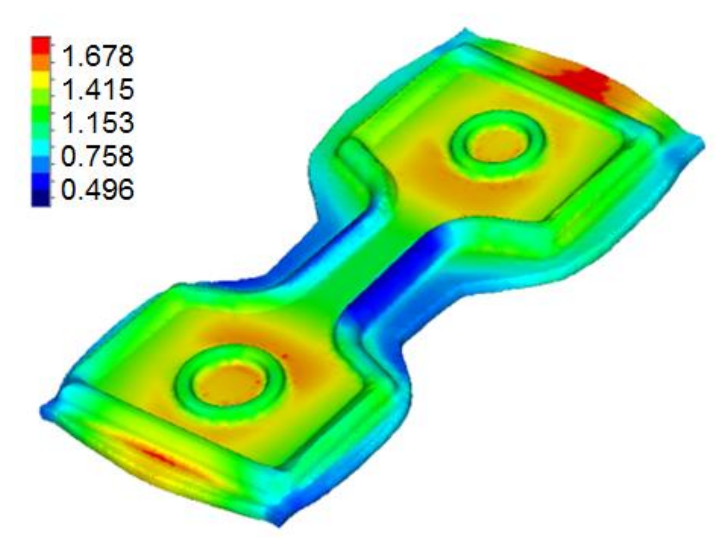

Figure 6. Total equivalent plastic strain

It is observed in the final connecting rod that the strain value is very homogeneous throughout the part. The central zone is the one with the lowest strain variation and the zones close to the two holes are those with the highest strain values. Nevertheless, the difference between the values of both zones is around $10 \%$.

\section{Experimental set-up}

Once the design process of the dies and the preform for obtaining a nanostructured single-piece connecting rod has been shown, its manufacturing is now tackled by a series of planned experimental tests in order to analyse the improvements which may be involved in the methodology proposed. As was previously mentioned, at present, there are no studies which show the manufacturing of connecting rods from ultra-fine grained material and therefore, this present research work is concerned with the development of connecting rods by means of an isothermal forging starting from ECAP-nanostructured AA1050 and AA5083 aluminium alloys.

This section shows the experimental design in order to carry out the study on the forging of a single-piece nanostructured connecting rod both from ultra-fine grained material and non-ultra-fine grained material. The main aim of this study is to analyse the differences obtained in the mechanical properties between the connecting rod forged both from annealed material and from ECAP ultra-fine grained material. In addition, the influence of the forging temperature is also studied.

\section{Attainment of the material}

The starting material consists of cylindrical aluminium billets with a diameter of $20 \mathrm{~mm}$ and a length of $120 \mathrm{~mm}$, as is shown in Figure 4 (a). The initial processing of the material consists in performing two ECAP passages with route $\mathrm{C}$, with which the billet is rotated $180^{\circ}$ in each passage.

The forging of the connecting rod is carried out in two stages. The first stroke allows a plane preform with no holes and ribs to be obtained, whereas the final part is obtained 
with the second stroke. Figure 7 (a) shows the connecting rod bottom die attached to the hydraulic press and Figure 7 (b) shows the starting billet set on the preform cavity. In order to save an additional forging stage, the ECAP-processed cylindrical billets are machined by a CNC lathe with the aim of reaching the previously designed dimensions for the preform.

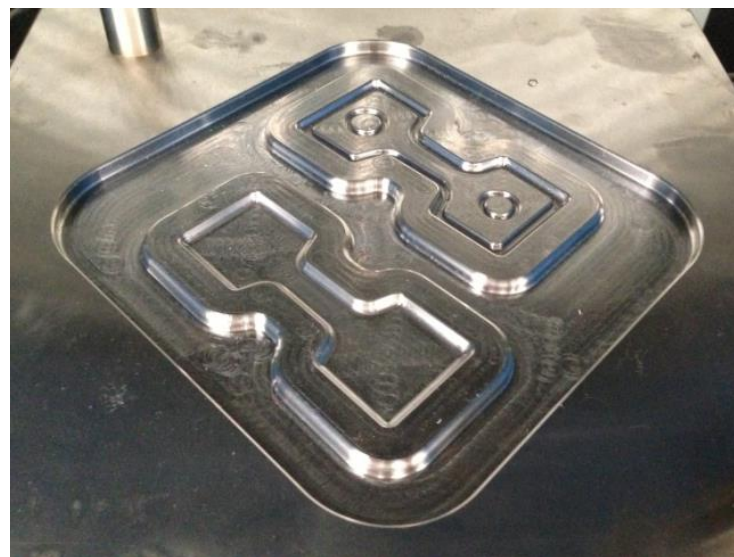

a) Bottom die

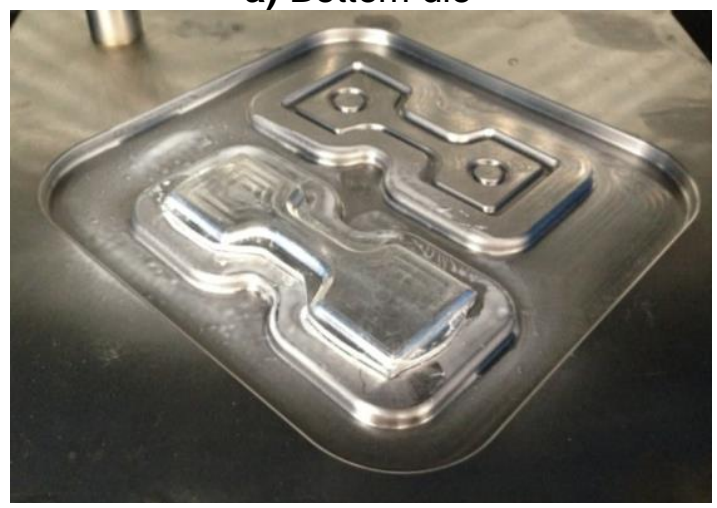

c) Preform after the $1^{\text {st }}$ forging stage

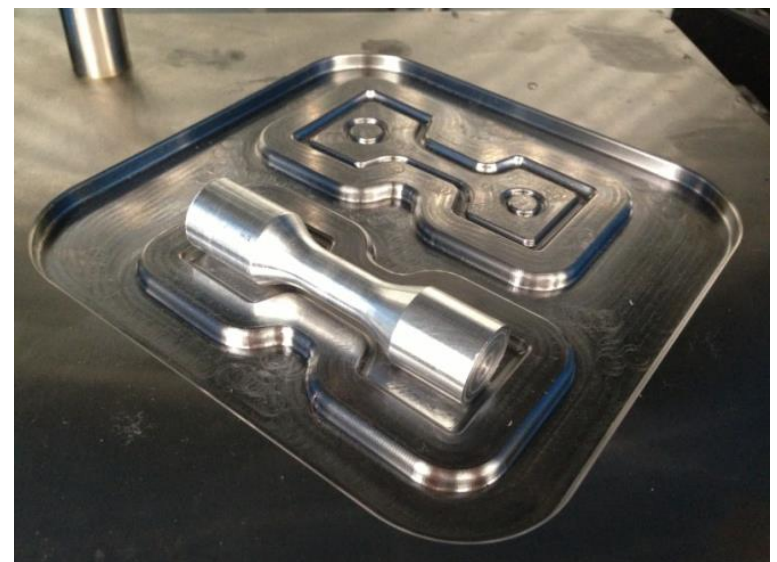

b) Billet on the bottom die

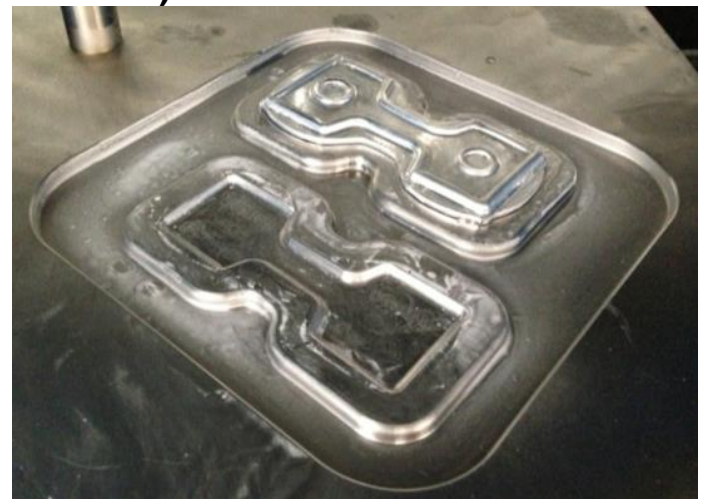

d) Connecting rod

Figure 7. Connecting rod dies

The forging is carried out at $30 \mathrm{~mm} / \mathrm{min}$. The dies are previously heated at the required temperature and once they reach that temperature value, the billet is placed on the die with a five-minute wait for the part to be at the same temperature as the forging dies. At this moment, the first stroke is performed over the billet (see Figure 7 (c)).

Subsequently, the preform is placed on the die cavity which belongs to the final design of the connecting rod to be forged and the second and definitive stroke is performed by isothermal forging. Figure 7 (d) shows the final connecting rod forged.

The different experimental tests carried out are shown below in order to study both the forgeability and the mechanical properties of the connecting rod designed which is manufactured from AA1050 and AA5083. 
In both material cases, the starting material is in the two states: NO (annealed material) and N2 (ECAP ultra-fine grained material twice with route C). In the case of AA1050, four isothermal forging temperatures are taken for $\mathrm{N} 0$ and $\mathrm{N} 2: 25^{\circ} \mathrm{C}, 75^{\circ} \mathrm{C}, 125^{\circ} \mathrm{C}$ and $175^{\circ} \mathrm{C}$. Nevertheless, in the case of AA5083, the forging temperature values are higher since this is an alloy with a higher hardness than AA1050. Therefore, the forging temperature values selected for $\mathrm{N} 0$ and $\mathrm{N} 2$ are as follows: $200{ }^{\circ} \mathrm{C}, 250{ }^{\circ} \mathrm{C}$ and $300^{\circ} \mathrm{C}$. In order to analyse the material mechanical properties, microhardness measurements are taken on each of the connecting rods forged. The experimental conditions for the microhardness tests (as regulated in the ISO 6507-1:2005 norm [24]) are as follows: a first time of $4 \mathrm{~s}$ for the approach, a load of $300 \mathrm{~g}$ is applied during $10 \mathrm{~s}$ and a final time of $4 \mathrm{~s}$ for the withdrawal of the penetrator. However, before taking the measurements, it is necessary to prepare the samples to be studied. To this end, each of the selected samples is embedded in resin and then it is subjected to a metallographic polishing. With the aim of achieving a mirror-like polished surface, several polishing stages with different sandpapers ranging from P600 to P2500 are needed. Subsequently, two final polishing stages with diamond suspensions of $1 \mu \mathrm{m}$ and $3 \mu \mathrm{m}$, respectively, are carried out. Later on, the microhardness measurements are taken on each of the zones of the samples. Starting from the strain pattern observed with the FEM simulations shown in Figure 6, the five zones of the connecting rod forged shown in Figure 8 are selected to be studied.

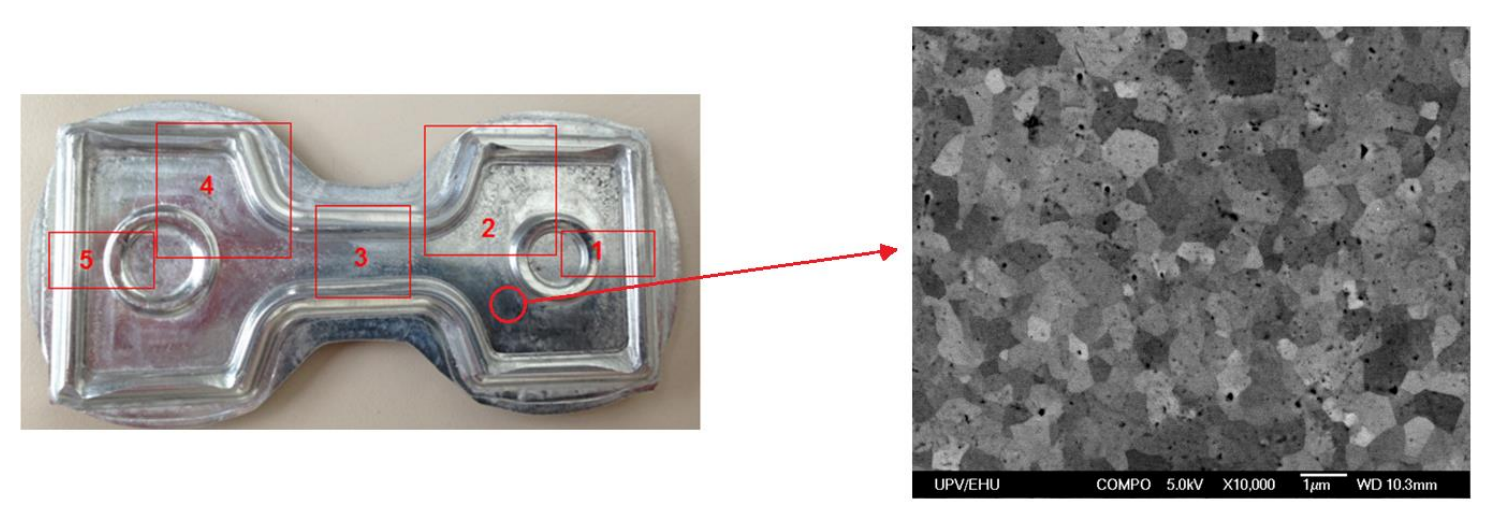

Figure 8. Microhardness zones

Taking the distribution into account, four measurements are taken at each of the zones since the strain pattern is rather homogeneous.

To complete the analysis of the mechanical properties, optical and SEM micrographs are also taken in order to be capable of observing the size and the distribution of the microstructure grains in detail, where its grain size reaches a value lower than $1 \mu \mathrm{m}$, as is shown in Figure 8. 


\section{Discussion of results}

After having shown the process design by finite element simulations, the experimental tests to be carried out and the analysis of the mechanical properties, this present section outlines the most important results obtained from the forging process.

When comparing the preform and the final connecting rod obtained by FEM and those experimentally obtained, it may be concluded that the predictions from the simulations are good, as can be observed in Figures 9 and 10. It may be observed that the small head has a higher amount of flash, whereas the design for the big head to be filled is very tight and as a consequence of this, there is very little amount of flash. It happens that at lower forging temperature values, the material does not fill the part completely. It is intended to optimise both the material flow and the processing force as much as possible in order to avoid an excessive amount of flash and to achieve a correct filling of the die cavity.

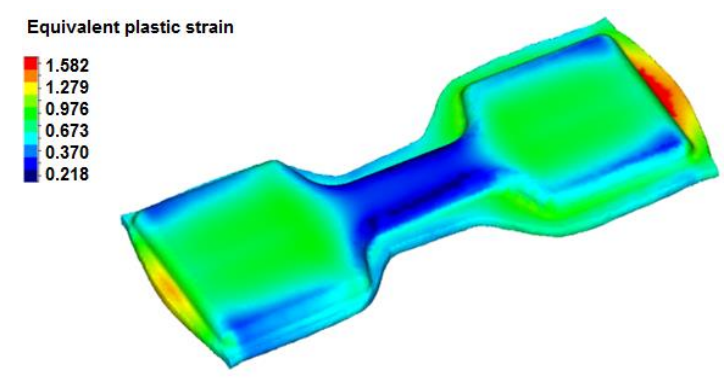

a) FEM preform

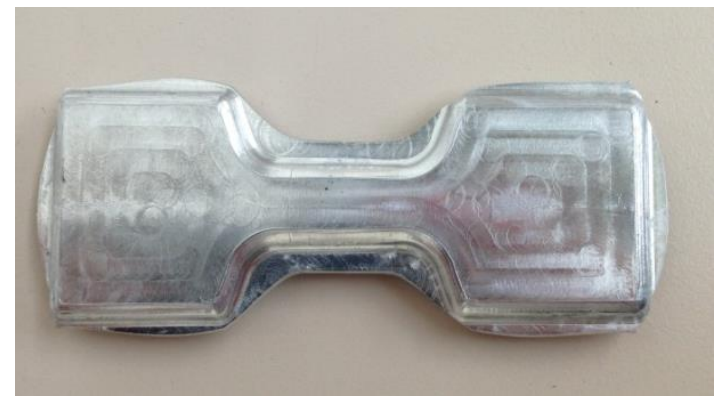

b) Experimental preform

Figure 9. Preform

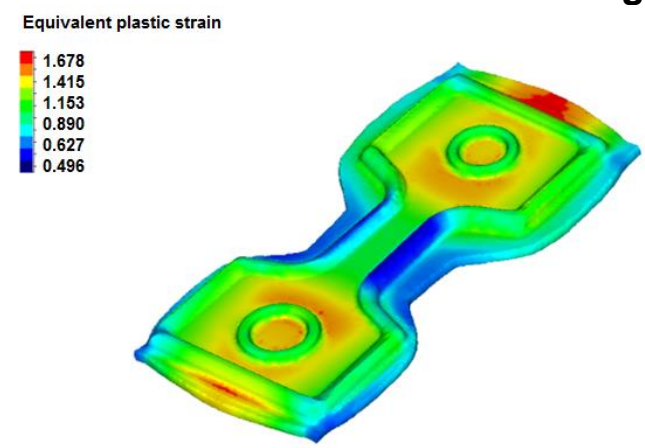

a) FEM connecting rod

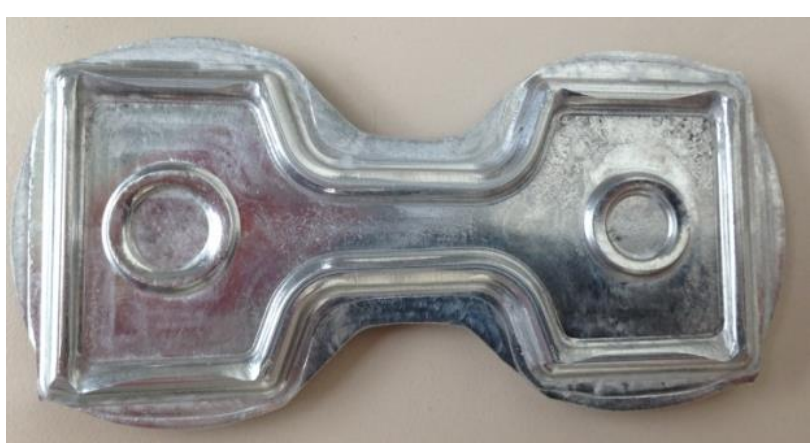

b) Experimental connecting rod

Figure 10. Connecting rod

\section{Forging force}

In order to analyse the forging force, load-stroke curves are plotted for each of the two strokes required to forge the connecting rod. With the help of a computer connected with the press, force and displacement data are measured and then treated in order to obtain the above-mentioned curves. 


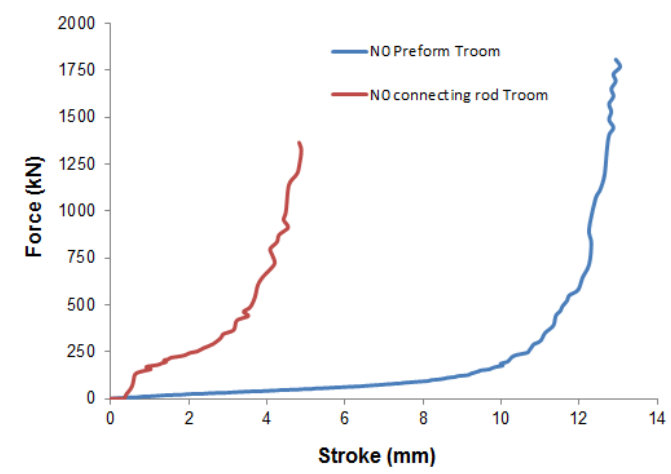

a) NO preform and N0 connecting rod

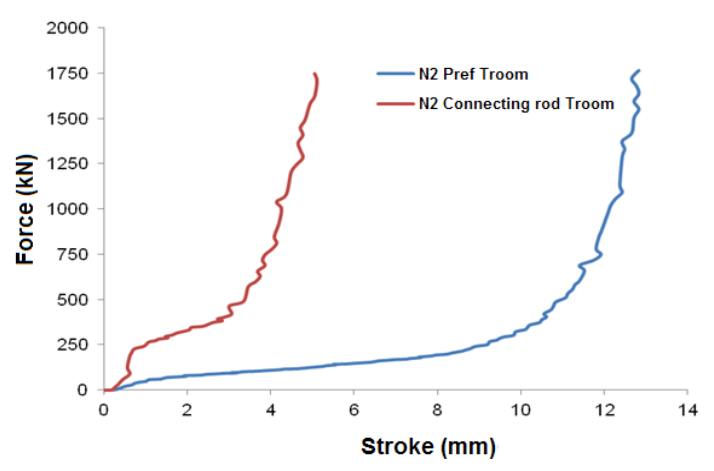

b) N2 preform and N2 connecting rod

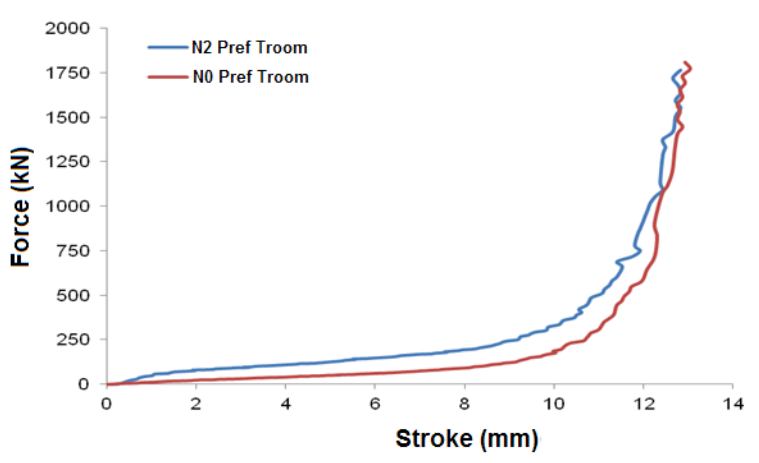

c) N0 preform and N2 preform

Figure 11. Load-stroke curves for AA1050

Figure 11 (a) shows the load-stroke curves corresponding to the first and to the second strokes which are required to manufacture the connecting rod from AA1050 N0 state. As is observed in Figure 11 (b), the limit force of $2000 \mathrm{kN}$ is reached more quickly for the second stroke. This is due to the fact that the material accumulates a higher strain value in the preform rather than in the starting material. Figure 11 (c) shows that the ultra-fine grained material with two ECAP passages requires a higher force level than the one which is not nanostructured. This is also due to the strain value accumulated in the ECAP process. For example, for a displacement of $6 \mathrm{~mm}$, the force required up to that moment in the case of the non-nanostructured billet is $65 \mathrm{kN}$, whereas in the case of that nanostructured with two ECAP passages, it is $165 \mathrm{kN}$.

\section{Microhardness}

Table 1 shows the microhardness measurements taken from all the connecting rod cases under consideration. As well as the values obtained, the part zones where these measurements are taken are shown in this table. Moreover, the microhardness mean value for each zone is shown as well as the standard deviation values, which enables the variability in the results to be analysed. 
Three strain measurements are taken from each of the zones shown in Figure 8 and the mean and the standard deviation values of these are calculated. The reason why three measurements are selected per each zone is due to the strain homogeneity that is observed in the results from the FEM simulations.

Table 1. Microhardness values (expressed in terms of Vickers Hardness number - HV) of $A A 1050$ and AA5083 connecting rods

\begin{tabular}{|c|c|c|c|c|}
\hline \multicolumn{5}{|c|}{ AA1050 N0 Trt } \\
\hline Zone 1 & Zone 2 & Zone 3 & Zone 4 & Zone 5 \\
\hline 44.5 & 44.3 & 39.2 & 46.6 & 47.0 \\
\hline 42.3 & 44.1 & 39.1 & 45.7 & 42.6 \\
\hline 45.2 & 45.4 & 39.5 & 45.8 & 47.1 \\
\hline 44.00 & 44.60 & 39.27 & 46.03 & 45.57 \\
\hline 1.51 & 0.70 & 0.21 & 0.49 & 2.57 \\
\hline MEAN & 43.89 & $\mathrm{SD}$ & .77 & \\
\hline
\end{tabular}

\begin{tabular}{|ccccc|}
\hline \multicolumn{5}{|c|}{ AA1050 N2 Trt } \\
\cline { 1 - 4 } Zone 1 & Zone 2 & Zone 3 & Zone 4 & Zone 5 \\
\cline { 5 - 5 } 53.4 & 50.0 & 47.6 & 50.3 & 54.4 \\
51.8 & 52.4 & 51.5 & 50.9 & 50.3 \\
50.8 & 51.6 & 49.3 & 50.9 & 53.4 \\
\hline 52.00 & 51.33 & 49.47 & 50.70 & 52.70 \\
1.31 & 1.22 & 1.96 & 0.35 & 2.14 \\
\hline MEAN: $\mathbf{5 1 . 2 4}$ & SD: 1.73 & \\
\hline
\end{tabular}

\begin{tabular}{|ccccc|}
\hline \multicolumn{5}{|c|}{ AA1050 N0 T75 } \\
\cline { 1 - 4 } Zone 1 & Zone 2 & Zone 3 & Zone 4 & Zone 5 \\
\cline { 5 - 6 } & 44.8 & 38.1 & 43.6 & 45.2 \\
44.1 & 45.0 & 38.1 & 43.0 & 44.8 \\
40.8 & 44.8 & 39.1 & 43.4 & 43.3 \\
\hline 42.97 & 44.87 & 38.43 & 43.33 & 44.43 \\
1.88 & 0.12 & 0.58 & 0.31 & 1.00 \\
\hline MEAN: 42.81 & SD: 2.52 & \\
\cline { 1 - 2 } & &
\end{tabular}

\begin{tabular}{|ccccc|}
\hline \multicolumn{5}{|c|}{ AA1050 N2 T75 } \\
\cline { 1 - 1 } Zone 1 & Zone 2 & Zone 3 & Zone 4 & Zone 5 \\
\cline { 5 - 6 } 49.5 & 48.6 & 47.7 & 49.8 & 48.4 \\
48.2 & 48.6 & 47.1 & 47.3 & 49.0 \\
47.3 & 48.9 & 48.4 & 48.5 & 50.2 \\
\hline 48.33 & 48.70 & 47.73 & 48.53 & 49.20 \\
1.11 & 0.17 & 0.65 & 1.25 & 0.92 \\
\hline MEAN: $\mathbf{4 8 . 5 0}$ & SD: 0.91 & \\
\hline
\end{tabular}

\begin{tabular}{|ccccc|}
\hline \multicolumn{5}{|c|}{ AA1050 N0 T125 } \\
\cline { 1 - 3 } Zone 1 & Zone 2 & Zone 3 & Zone 4 & Zone 5 \\
\hline 40.0 & 46.1 & 36.0 & 41.2 & 41.9 \\
40.8 & 45.2 & 36.8 & 41.7 & 42.5 \\
41.9 & 45.5 & 36.6 & 41.5 & 42.8 \\
\hline 40.90 & 45.60 & 36.47 & 41.47 & 42.40 \\
0.95 & 0.46 & 0.42 & 0.25 & 0.46 \\
\hline MEAN: 41.37 & SD: 3.08 & \\
\cline { 1 - 2 } & &
\end{tabular}

\begin{tabular}{|ccccc|}
\hline \multicolumn{5}{|c|}{ AA1050 N2 T125 } \\
\cline { 1 - 3 } Zone 1 & Zone 2 & Zone 3 & Zone 4 & Zone 5 \\
\cline { 5 - 6 } 47.4 & 47.3 & 47.6 & 48.8 & 47.4 \\
45.0 & 46.8 & 48.9 & 48.5 & 49.1 \\
44.9 & 45.1 & 48.5 & 48.1 & 45.8 \\
\hline 45.77 & 46.40 & 48.33 & 48.47 & 47.43 \\
1.42 & 1.15 & 0.67 & 0.35 & 1.65 \\
\hline MEAN: 47.28 & SD: 1.47 & \\
\hline
\end{tabular}

\begin{tabular}{|ccccc|}
\hline \multicolumn{5}{|c|}{ AA1050 N0 T175 } \\
\cline { 1 - 3 } Zone 1 & Zone 2 & Zone 3 & Zone 4 & Zone 5 \\
\cline { 3 - 4 } 44.2 & 39.8 & 36.7 & 40.1 & 43.9 \\
42.8 & 40.0 & 36.8 & 40.2 & 45.7 \\
42.5 & 40.2 & 36.9 & 40.3 & 42.6 \\
\hline 43.17 & 40.00 & 36.80 & 40.20 & 44.07 \\
0.91 & 0.20 & 0.10 & 0.10 & 1.56 \\
\hline MEAN: 40.85 & SD: 2.76 & \\
\cline { 1 - 2 } &
\end{tabular}

\begin{tabular}{|ccccc|}
\hline \multicolumn{5}{|c|}{ AA1050 N2 T175 } \\
\cline { 1 - 3 } Zone 1 & Zone 2 & Zone 3 & Zone 4 & Zone 5 \\
\hline 45.0 & 48.1 & 45.6 & 47.8 & 45.4 \\
46.4 & 47.5 & 45.8 & 47.4 & 45.6 \\
46.7 & 47.3 & 48.7 & 47.0 & 46.0 \\
\hline 46.03 & 47.63 & 46.70 & 47.40 & 45.67 \\
0.91 & 0.42 & 1.73 & 0.40 & 0.31 \\
\hline MEAN: 46.69 & \multicolumn{5}{|c|}{ SD: 1.11 } \\
\hline
\end{tabular}




\begin{tabular}{|c|c|c|c|c|}
\hline \multicolumn{5}{|c|}{ Zone 1 Zone 2 Zone 3 Zone 4 Zone 5} \\
\hline 115.8 & 108.7 & 112.6 & 119.0 & 108.7 \\
\hline 111.9 & 106.1 & 115.8 & 116.8 & 111.2 \\
\hline 113.3 & 113.7 & 116.8 & 114.2 & 109.9 \\
\hline 113.7 & 10 & 11 & 116.7 & 109.9 \\
\hline 1.98 & 3.86 & 2.19 & 2.40 & 1.25 \\
\hline \multicolumn{2}{|c|}{ MEAN: 112.97} & \multicolumn{2}{|c|}{ SD: $\mathbf{3 . 6 0}$} & \\
\hline
\end{tabular}

\begin{tabular}{|c|c|c|c|c|}
\hline Zone & Zone 2 & Zon & Zone 4 & Zone 5 \\
\hline 135.6 & 132.7 & 128.9 & 134.9 & 131.5 \\
\hline 128.8 & 135.0 & 131.6 & 130.7 & 128.8 \\
\hline 130.0 & 136.6 & 131.7 & 136.3 & 127.5 \\
\hline 131.5 & 134.8 & 130.7 & 134.0 & 129.3 \\
\hline 3.63 & 1.96 & 1.59 & 2.91 & 2.04 \\
\hline \multicolumn{2}{|c|}{ MEAN: 132.04} & \multicolumn{2}{|c|}{ SD: $\mathbf{3 . 0 1}$} & \\
\hline
\end{tabular}

\begin{tabular}{|ccccc|}
\hline \multicolumn{5}{|c|}{ AA5083 N0 T250 } \\
\cline { 1 - 4 } Zone 1 & Zone 2 & Zone 3 & Zone 4 & Zone 5 \\
\cline { 1 - 4 } 99.2 & 100.6 & 96.3 & 105.6 & 96.9 \\
101.4 & 103.9 & 100.8 & 99.1 & 95.0 \\
103.4 & 99.6 & 100.9 & 103.1 & 99.2 \\
\hline 101.3 & 101.3 & 99.3 & 102.7 & 97 \\
2.10 & 2.25 & 2.63 & 3.07 & 2.10 \\
\hline MEAN: 100.36 & SD: 2.92 & \\
\cline { 1 - 2 } &
\end{tabular}

\begin{tabular}{|ccccc|}
\hline \multicolumn{5}{|c|}{ AA5083 N2 T250 } \\
\cline { 1 - 4 } Zone 1 & Zone 2 & Zone 3 & Zone 4 & Zone 5 \\
\cline { 1 - 4 } 112.7 & 111.5 & 108.9 & 111.8 & 111.3 \\
112.6 & 110.2 & 109.1 & 109.9 & 111.8 \\
113.2 & 110.8 & 108.3 & 110.2 & 108.4 \\
\hline 112.8 & 110.8 & 108.8 & 110.6 & 110.5 \\
0.32 & 0.65 & 0.42 & 1.02 & 1.84 \\
\hline MEAN: 110.71 & SD: 1.59 & \\
\hline
\end{tabular}

\begin{tabular}{|ccccc|}
\hline \multicolumn{5}{|c|}{ AA5083 N0 T300 } \\
\cline { 1 - 3 } Zone 1 & Zone 2 & Zone 3 & Zone 4 & Zone 5 \\
\hline 93.5 & 90.3 & 90.8 & 90.2 & 90.5 \\
92.4 & 92.2 & 91.8 & 90.9 & 90.6 \\
92.4 & 87.8 & 91.5 & 89.6 & 89.3 \\
\hline 92.8 & 90.1 & 91.4 & 90.2 & 90.1 \\
0.64 & 2.21 & 0.51 & 0.65 & 0.72 \\
\hline MEAN: $\mathbf{9 0 . 9 2}$ & \multicolumn{3}{|c|}{ SD: 1.44 } & \\
\cline { 1 - 2 } &
\end{tabular}

\begin{tabular}{|ccccc|}
\hline \multicolumn{5}{|c|}{ AA5083 N2 T300 } \\
\cline { 1 - 3 } Zone 1 & Zone 2 & Zone 3 & Zone 4 & Zone 5 \\
\hline 93.4 & 94.6 & 94.0 & 94.1 & 94.3 \\
94.9 & 94.9 & 93.5 & 94.3 & 94.2 \\
94.3 & 93.8 & 93.1 & 95.1 & 94.4 \\
\hline 94.2 & 94.4 & 93.5 & 94.5 & 94.3 \\
0.75 & 0.57 & 0.45 & 0.53 & 0.10 \\
\hline MEAN: $\mathbf{9 4 . 1 9}$ & \multicolumn{3}{|c|}{ SD: 0.57 } & \\
\hline
\end{tabular}

In the results obtained in the finite element simulations (see Figures 12 (a) to 12 (h)), it may be observed that the zones where there is a higher plastic strain value are zones 2 and 4 , as occurs in the experimental tests. Nevertheless, it may be appreciated that the strain value varies very little in each test, where this variation is lower than that obtained in the experimental tests. On the other hand, it is possible to appreciate that the strain value is higher in the connecting rods simulated with an AA1050 flow rule with two ECAP passages and route $C$ rather than in the case of the non-nanostructured AA1050.
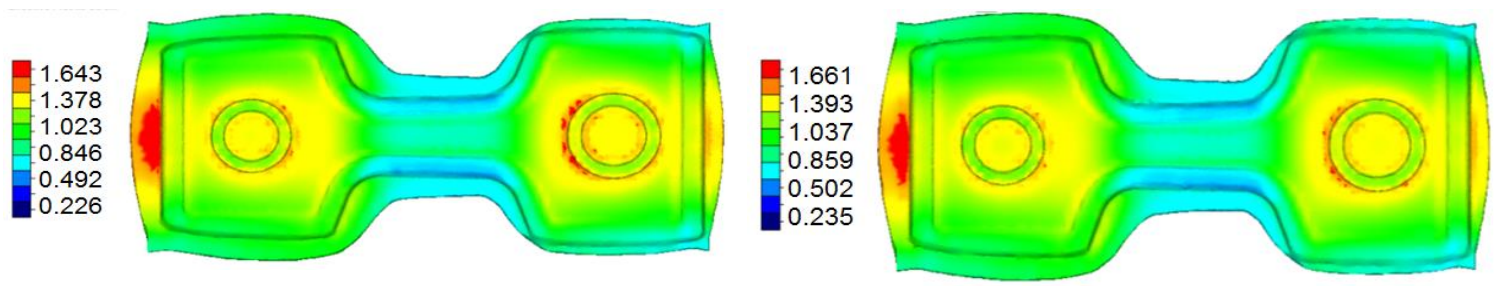

a) Connecting rod forged at $25^{\circ} \mathrm{C}$ from

b) Connecting rod forged at $75^{\circ} \mathrm{C}$ from 


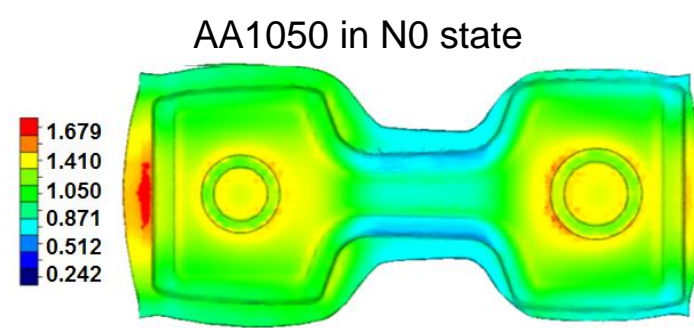

c) Connecting rod forged at $125^{\circ} \mathrm{C}$ from AA1050 in N0 state

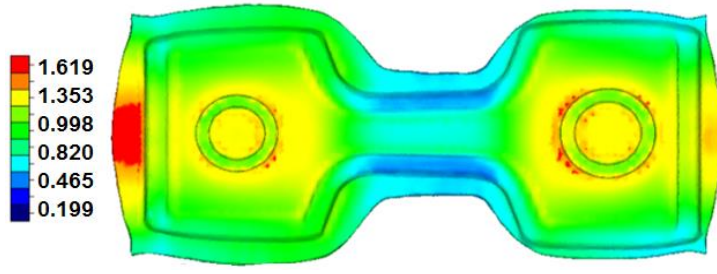

e) Connecting rod forged at $25^{\circ} \mathrm{C}$ from AA1050 in N2 state

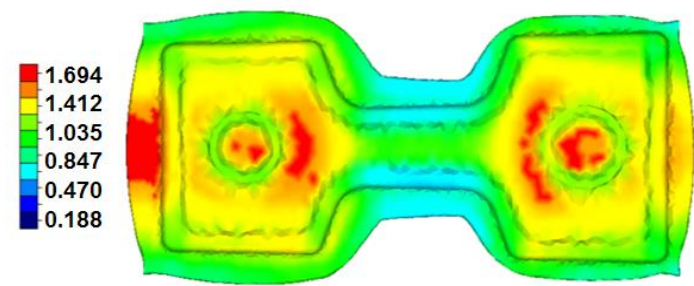

g) Connecting rod forged at $125^{\circ} \mathrm{C}$ from

AA1050 in N2 state

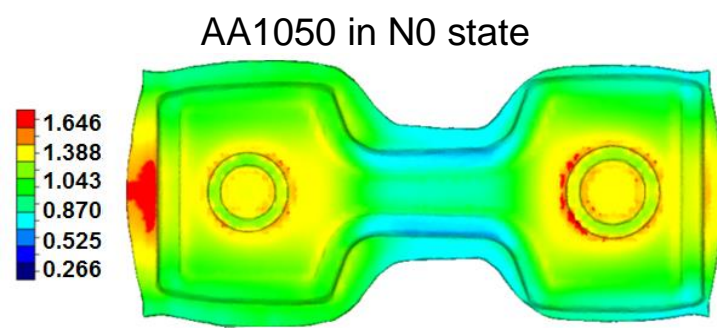

d) Connecting rod forged at $175^{\circ} \mathrm{C}$ from AA1050 in N0 state

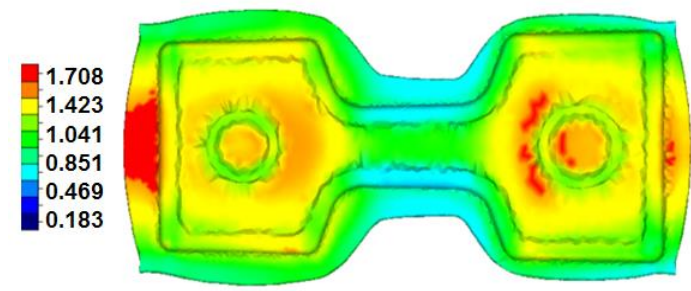

f) Connecting rod forged at $75^{\circ} \mathrm{C}$ from AA1050 in N2 state

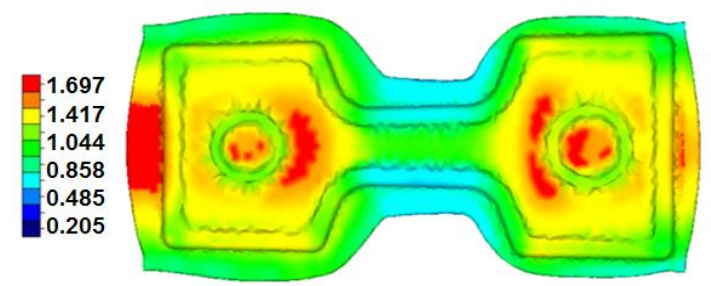

h) Connecting rod forged at $175^{\circ} \mathrm{C}$ from AA1050 in N2 state

Figure 12. Strain values obtained in the simulations for the AA1050 connecting rod

Figure 13 shows the microhardness mean values for each connecting rod zone and for each forging temperature. These results belong to the connecting rod with the AA1050 starting material in NO state. It is observed in each of the four curves for the different temperature values that the zone with the lowest hardness value is the central zone and the zones close to the holes are those with the highest hardness values. The results obtained correspond to those observed in the finite element simulations. It is observed, as expected, that hardness decreases as the forging temperature is increased, except in the case of the curve for the forging at $175^{\circ} \mathrm{C}$. This may be due to the fact that all the values are very similar and they are found within the measuring variability. 


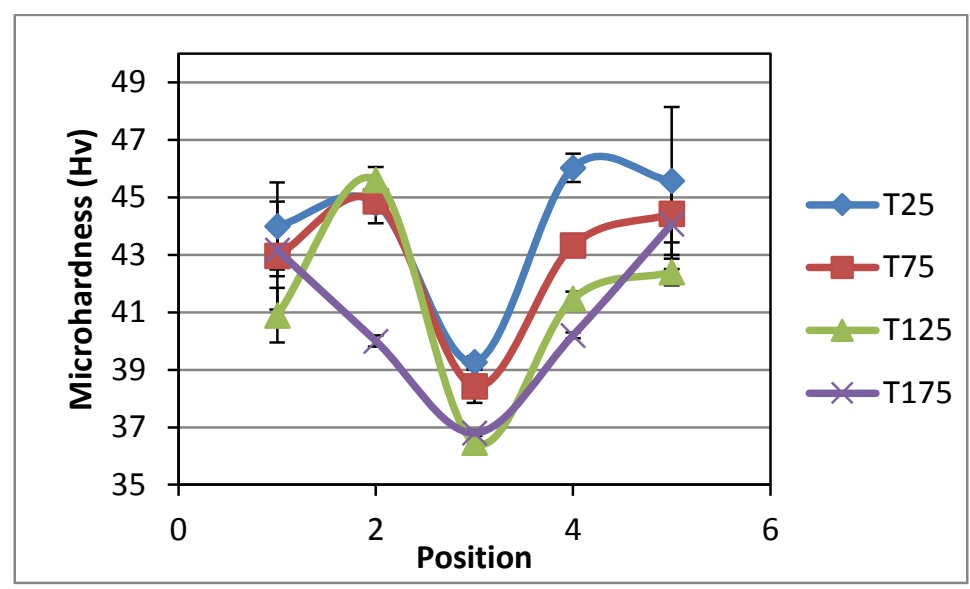

Figure 13. Microhardness for AA1050 in N0 state

Figure 14 plots the same curves as those shown in Figure 13 but in this case for the connecting rod with the AA1050 starting material which is ECAP-processed twice. In the case of the curves at $25^{\circ} \mathrm{C}$ and $75{ }^{\circ} \mathrm{C}$, the zones with the highest strain values are those close to the holes, where the central zone is the one which has the lowest strain value. However, at $125^{\circ} \mathrm{C}$ and $175^{\circ} \mathrm{C}$, this behaviour pattern is not observed, where this may occur because of the anisotropy which has the initial billet ECAP-processed twice [25]. Depending on how the initial billet is placed in the forging die, the plastic strain inside this is distributed in a different manner during the forging process.

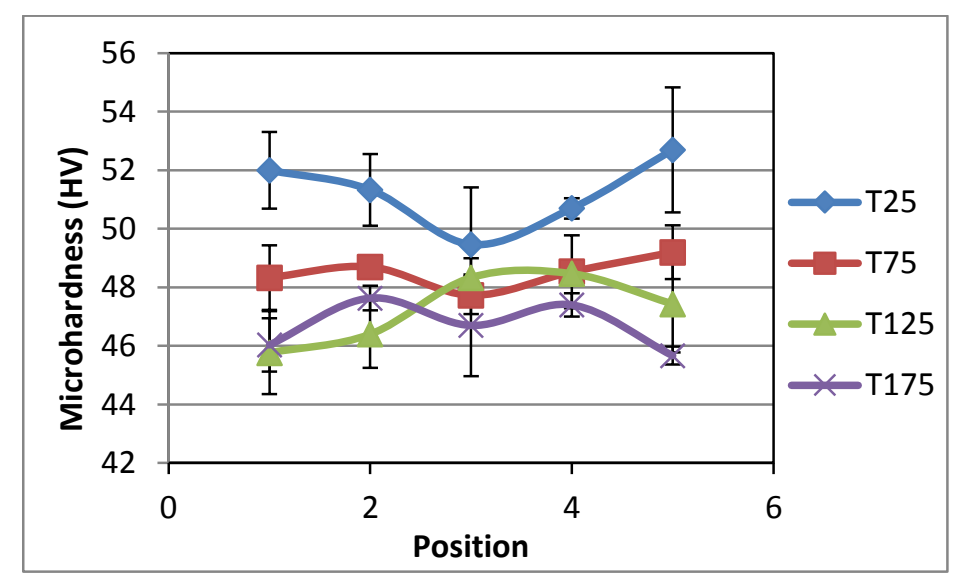

Figure 14. Microhardness for AA1050 in N2 state

Figures 15 and 16 show the microhardness results obtained for AA5083. As occurs in the case of the $A A 1050$, there are differences observed in the results corresponding to AA5083 microhardness in N0 and N2 states. The microhardness values obtained in the case of AA5083 in N0 state are shown in Figure 15. The highest microhardness values are obtained in the case of the connecting rod forged at $200{ }^{\circ} \mathrm{C}$, where the difference observed for microhardness is $20 \%$ in relation to the connecting rod forged at $300{ }^{\circ} \mathrm{C}$. 


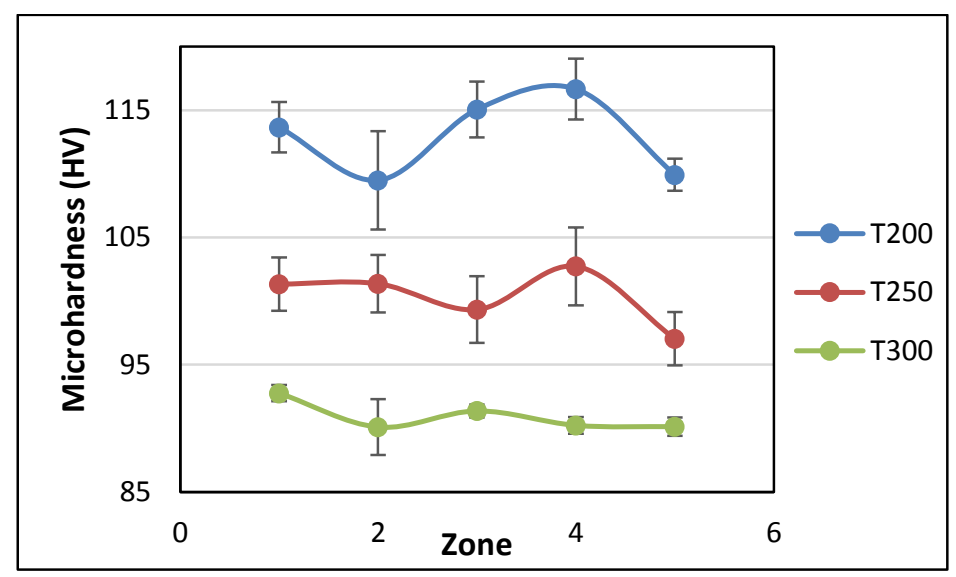

Figure 15. Microhardness for AA5083 in N0 state

Figure 16 shows the microhardness values obtained for the connecting rods forged from ECAP ultra-fine grained material (N2). The increase in hardness is significant and it is $15 \%$ in relation to the non-ultra-fine grained material. The highest microhardness values are reached in the case of the isothermal forging at $200^{\circ} \mathrm{C}$, where there is a decrease in the mean value of about $30 \%$ in relation to the forging process at $300{ }^{\circ} \mathrm{C}$.

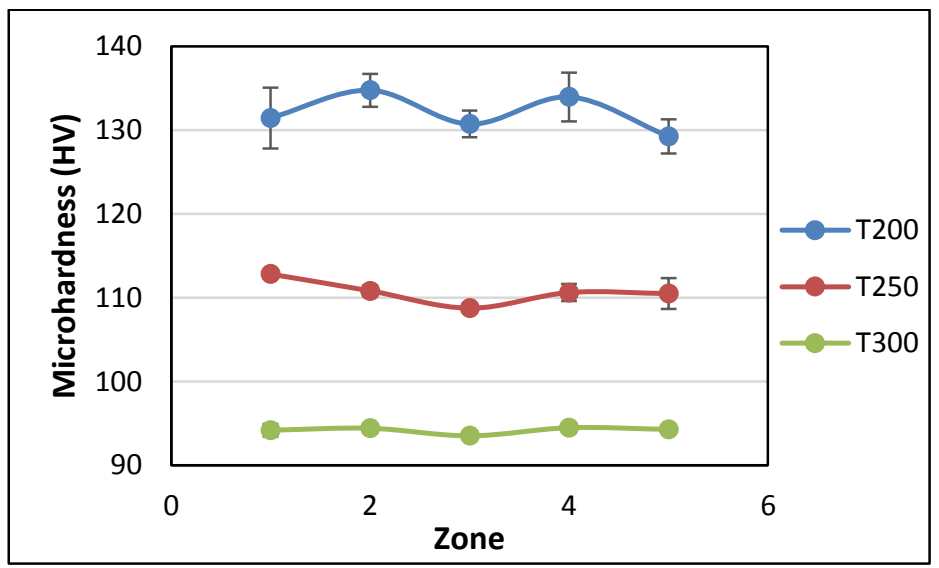

Figure 16. Microhardness for AA5083 in N2 state

Once the results obtained for each study case have been analysed, Figure 17 shows a comparison for the microhardness mean values between the connecting rods with N0 and N2 as starting materials. Figure 17 (a) clearly shows that hardness is about $20 \%$ higher in the case of the AA1050 connecting rods with the N2 state and therefore, there exists a significant improvement in the mechanical properties starting from a previously ultra-fine grained material. In addition, the variability in the data is higher in the case of the microhardness measurements taken from the ECAP-processed material, where this may be caused by the anisotropy which the material presents. The same effect may be observed in Figure 17 (b) for the case of AA5083, with the only difference 
being that at a temperature of $300 \stackrel{\circ}{ } \mathrm{C}$, the microhardness values are practically the same due to the fact that grain growth occurs.

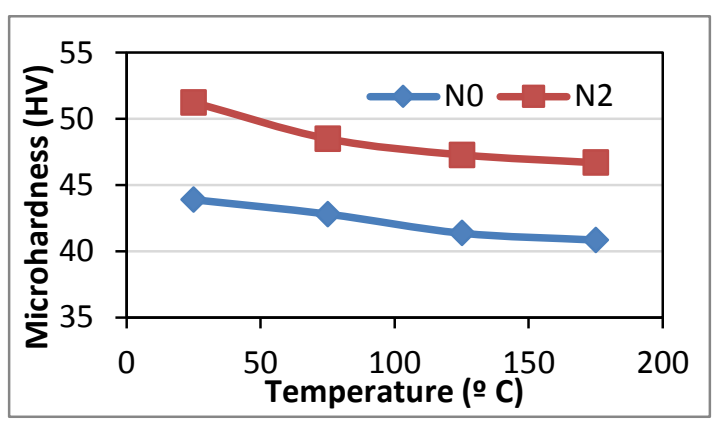

a) AA1050

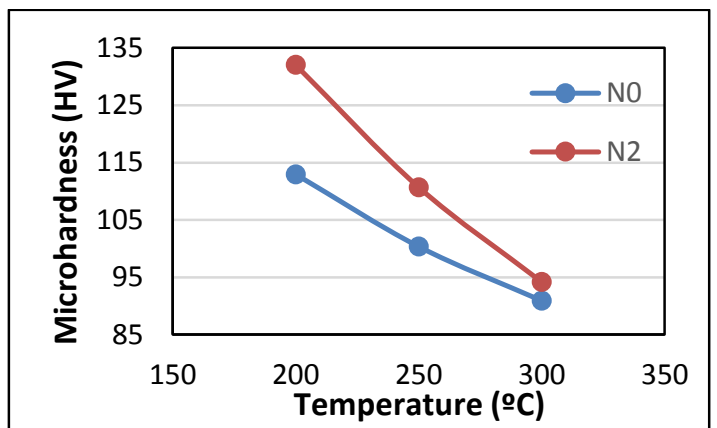

b) AA5083

Figure 17. Microhardness values for N0 and N2

Moreover, Figure 18 shows four optical micrographs with regard to the N0 and N2 states of the two aluminium alloys under consideration in this present research work (AA1050 and AA5083). In relation to their grain size value, it may be observed that AA1050 has a grain size value higher than AA5083 both for N0 and N2 states. This means that $A A 1050$ is a softer aluminium alloy in comparison with $A A 5083$, as may be observed from the microhardness values obtained after the forging process for the manufactured connecting rods. If the two starting states for each aluminium alloy are compared, it may be observed that the microstructure of the ECAP-processed materials presents deformation bands inside the grains, which leads to a harder material and thus with a higher value of mechanical strength, as the microhardness measurements reveal.

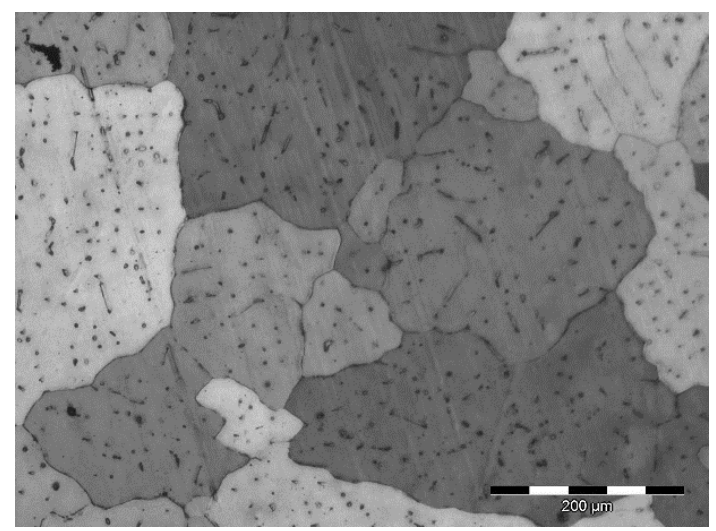

a) $\mathrm{AA} 1050 \mathrm{~N} 0$

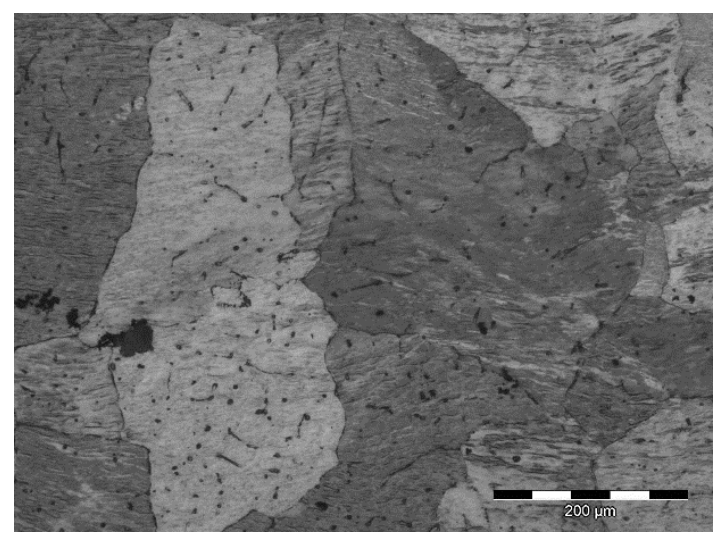

b) $\mathrm{AA} 1050 \mathrm{~N} 2$ 


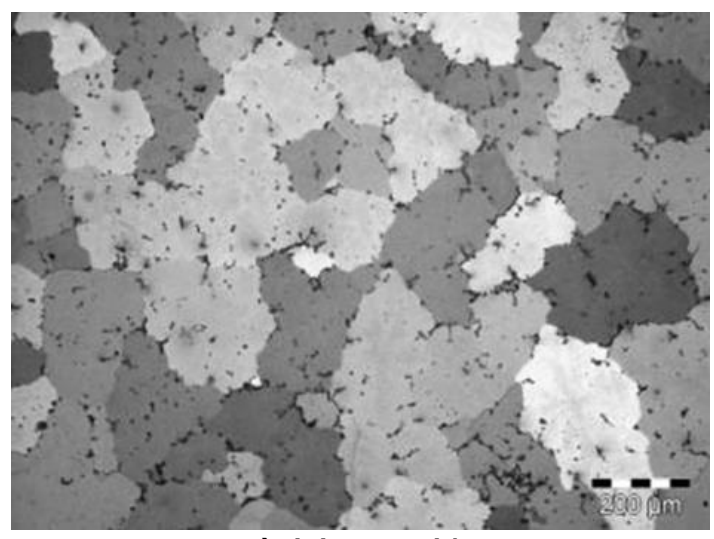

c) AA5083 N0

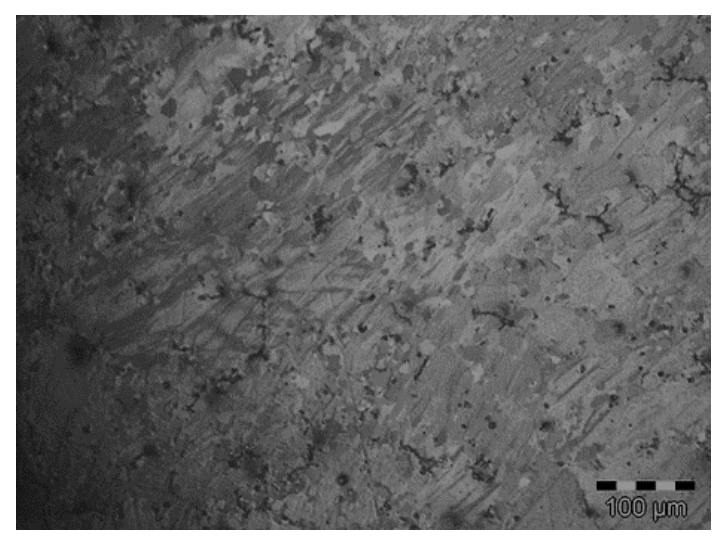

d) AA5083 N2

Figure 18. Optical micrographs for AA1050 and AA5083 in N0 and N2 states

Two optical micrographs for different forging cases and taken from zone 3 are shown in Figure 19. Figure 19 (a) corresponds to the connecting rod forged at $25 \stackrel{\circ}{\circ}$ from nonultra-fine grained material, whereas in the case of Figure 19 (b), the starting material is previously ECAP-nanostructured. It may be observed that in the case of Figure 19 (a) the grain distribution is more uniform and equiaxial. Nevertheless, in the case of Figure 19 (b), grains are deformed and the shape has become elliptical, where the major axis of these is aligned in the same direction. This is because of the two previous ECAP passages that the material undergoes before being forged.

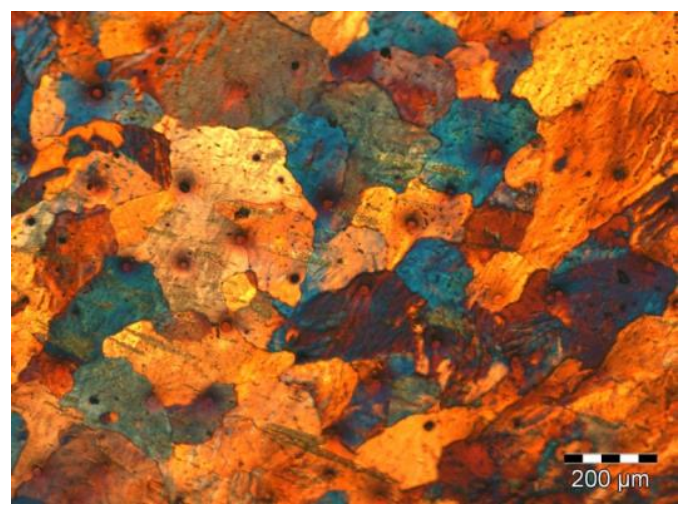

a) Connecting rod forged at $25^{\circ} \mathrm{C}$ from AA1050 in N0 state (zone 3)

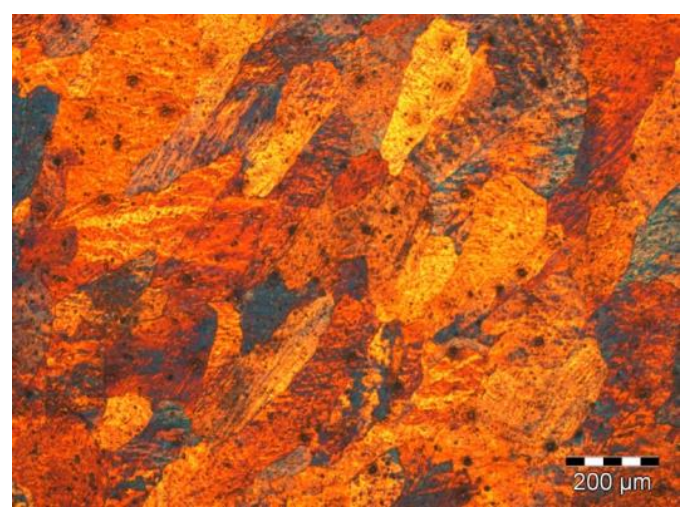

b) Connecting rod forged at $25^{\circ} \mathrm{C}$ from AA1050 in N2 state (zone 3)

Figure 19. Optical micrographs

In order to complete this present research work, SEM micrographs are taken from the connecting rods with ultra-fine grained material so that it is possible to clearly observe the grain size and its distribution throughout the microstructure. A uniform distribution of grain is observed in Figures 20 (a) and (b) with nanometric grain size values. It may be observed that there are grains with a size lower than $500 \mathrm{~nm}$. Grains with a lower size than those at $25^{\circ} \mathrm{C}$ may be observed in Figure 20 (c), where these seem to be located inside a former grain, thus signifying that the material is recrystallized. Figure 
20 (d) shows a very similar situation where the material also seems to have undergone a recrystallization process.

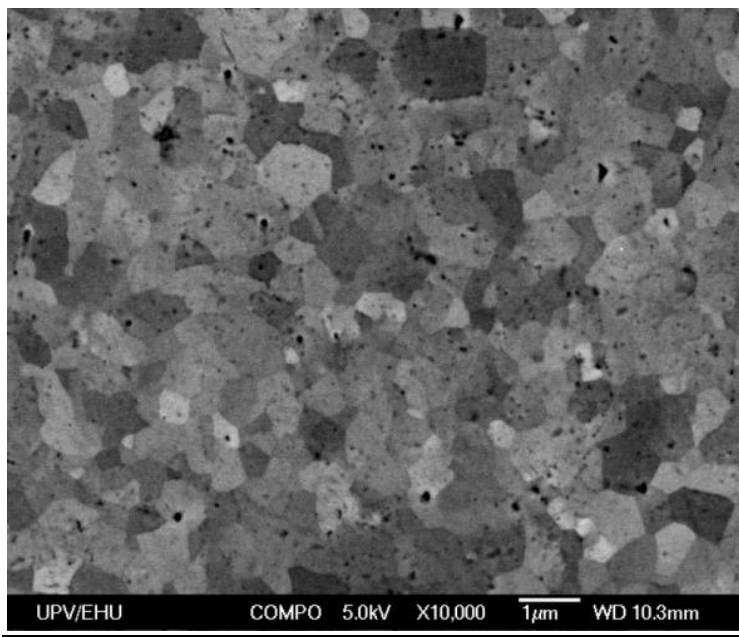

a) Connecting rod forged at $25^{\circ} \mathrm{C}$ from AA1050 in N2 state (zone 3 at 10000x)

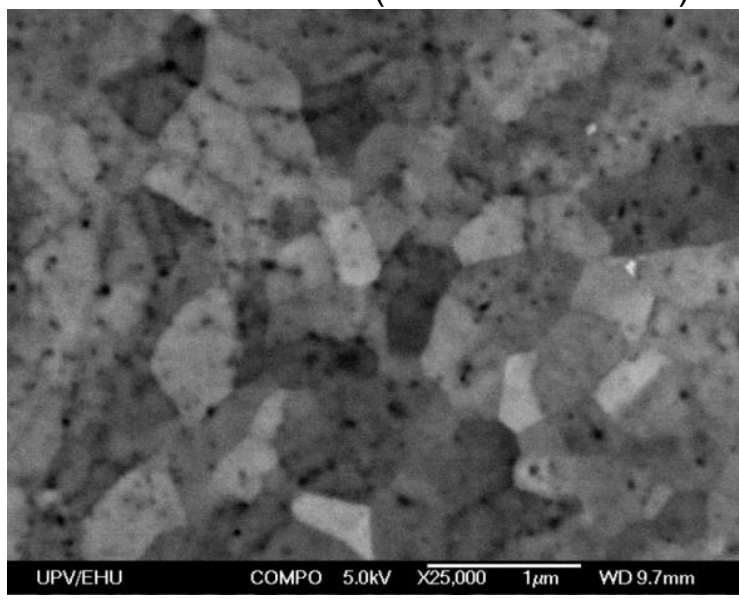

c) Connecting rod forged at $125 \stackrel{\circ}{\mathrm{C}}$ from AA1050 in N2 state (zone 3 at 25000x)

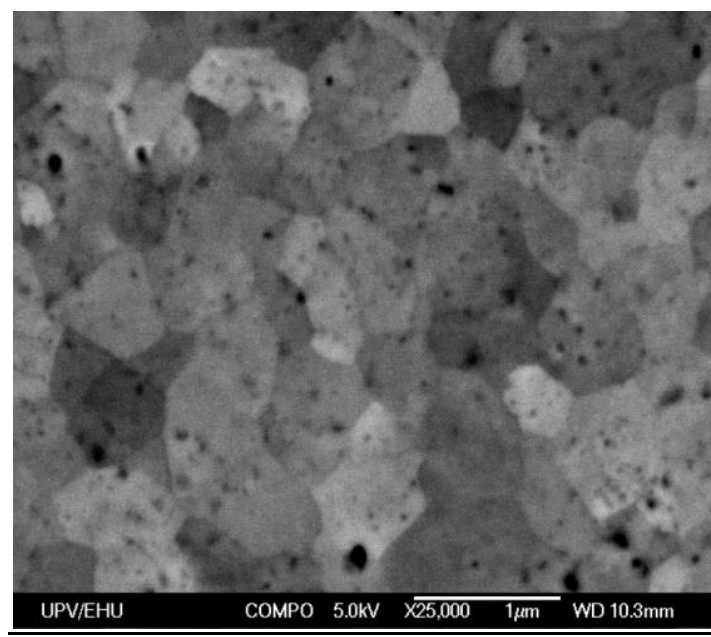

b) Connecting rod forged at $25^{\circ} \mathrm{C}$ from AA1050 in N2 state (zone 3 at 25000x)

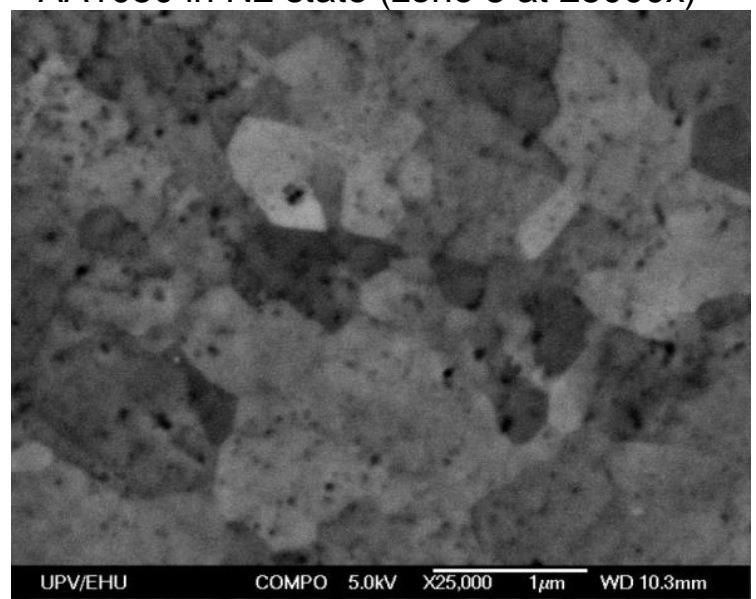

d) Connecting rod forged at $175^{\circ} \mathrm{C}$ from AA1050 in N2 state (zone 3 at 25000x)

Figure 20. SEM micrographs

\section{Conclusions}

In this present research work, forging of single-piece connecting rods from AA1050 and AA5083 previously ECAP-nanostructured is studied by finite element simulations and experimental tests. The results obtained by FEM are in good agreement with reality.

Both mechanical properties and microstructure from the connecting rods manufactured are studied by microhardness tests along with optical and SEM microscopy.

In spite of the fact that the material under study (AA1050) presents a low level of strain hardening, a significant improvement in hardness is obtained in the case of the connecting rods manufactured from ultra-fine grained material. The increase in hardness is about $20 \%$. 
The manufacturing of connecting rods from ultra-fine grained material at room temperature is achieved with a good filling of the die cavity in the case of AA1050. In addition, forging tests are carried out at different temperature values $\left(25^{\circ} \mathrm{C}, 75^{\circ} \mathrm{C}, 125\right.$ ${ }^{\circ} \mathrm{C}$ and $175^{\circ} \mathrm{C}$ ), where it is found that a lower hardness value takes place when forging temperature increases. It is observed by scanning electron microscopy that at $175^{\circ} \mathrm{C}$, dynamic recrystallization starts to take place in the case of the previously ECAPprocessed billets.

Furthermore, connecting rods are manufactured from nanostructured AA5083. In the same way as with AA1050, connecting rods are experimentally forged (at $200^{\circ} \mathrm{C}, 250$ ${ }^{\circ} \mathrm{C}$ and $300^{\circ} \mathrm{C}$ ) and microhardness measurements are taken in order to analyse the mechanical properties of the material.

Finally, it may be concluded that this present research work presents an efficient way of obtaining mechanical components with high resistance, specifically in those aluminium alloys, such as AA1050, which have a low value of strain hardening.

\section{Acknowledgements}

The authors of this present research work acknowledge the support given by the Ministry of Economy and Competitiveness from Spain, through the Research Projects DPI2010-18941 and DPI2013-41954-P.

\section{References}

[1] Segal VM, Reznikov VI, Drobyshevskiy AE, Kopylov VI. Plastic working of metals by simple shear. Russ Metall 1981; 1:99-105.

[2] Luri R, Luis Pérez CJ, Salcedo D, Puertas I, León J, Pérez I, Fuertes JP. Evolution of damage in AA-5083 processed by equal channel angular extrusion using different die geometries. J Mater Process Technol 2011; 211(1):48-56.

[3] Segal VM. Mechanics of continuous equal-channel angular extrusion. J Mater Process Technol 2010; 210(3):542-549.

[4] Luis CJ, Salcedo D, León J, Puertas I, Fuertes JP, Luri R. Manufacturing of nanostructured rings from previously ECAE processed AA5083 alloy by isothermal forging. J Nanomater 2013; 1-14, Article ID 613102.

[5] Puertas I, Luis Pérez CJ, Salcedo D, León J, Fuertes JP, Luri R. Design and mechanical property analysis of AA1050 turbine blades manufactured by equal channel angular extrusion and isothermal forging. Mater Design 2013; 52:774-784.

[6] Takemasu T, Vazquez V, Painter B, Altan T. Investigation of metal flow and preform optimization in flashless forging of a connecting rod. $\mathrm{J}$ Mater Process Technol 1996; 59(1-2):95-105.

[7] Vazquez V, Altan T. Die design for flashless forging of complex parts. J Mater Process Technol 2000; 98:81-89.

[8] Grass H, Krempaszky C, Reip T, Werner E. 3-D Simulation of hot forming and microstructure evolution. Comp Mater Sci 2003; 28:469-477.

[9] Grass H, Krempaszky C, Werner E. 3-D FEM-simulation of hot forming processes for the production of a connecting rod. Computational Mater Sci 2006; 36:480-489.

[10] Chen D-C, Chen W-J, Lin J-Y, Jheng M-W, Chen J-M. Finite element analysis of 
superplastic blow-forming of Ti-6Al-4V sheet into closed ellip-cylindrical die. Int $\mathrm{J}$ Simul Model 2010; 9(1):17-27.

[11] Dezelak M, Stepisnik A, Pahole I, Ficko M. Evaluation of twist springback prediction after an AHSS forming process. Int J Simul Model 2014; 13(2):171-182.

[12] Yin F, Wang GX, Hong SZ, Zeng ZP. Technological study of liquid die forging for the aluminum alloy connecting rod of an air compressor. J Mater Process Technol 2003; 139:462-464.

[13] Wang Q, He F. A review of developments in the forging of connecting rods in China. J Mater Process Technol 2004; 151:192-195.

[14] Lovrec D, Kastrevc M. Modelling and simulating a controlled press-brake supply system. Int J Simul Model 2011; 10(3):133-144.

[15] Qiu JW, Liu Y, Liu YB, Liu B, Wang B, Ryba E, Tang HP. Microstructures and mechanical properties of titanium alloy connecting rod made by powder forging process. Mater Design 2012; 33:213-219.

[16] Chen N, Han L, Zhang W, Hao X. Enhancing mechanical properties and avoiding cracks by simulation of quenching connecting rods. Mater Letters 2007; 61:30213024.

[17] Khare S, Singh OP, Bapanna Dora K, Sasun C. Spalling investigation of connecting rod. Eng Fail Anal 2012; 19:77-86.

[18] Luri R, Luis CJ, Salcedo D, León J, Fuertes JP, Puertas I. FEM analysis of the isothermal forging of a connecting rod from material previously deformed by ECAE. Procedia Engineering 2013; 63:540-546.

[19] Alhajeri SN, Gao N, Langdon TG. Hardness homogeneity on longitudinal and transverse sections of an aluminum alloy processed by ECAP. Mater Sci Eng AStruct Mater Prop Microstruct Process 2011; 528(10-11):3833-3840.

[20] Luis CJ, León J, Luri R, Puertas I, Pérez I, Salcedo D. Development of nanostructured AA1050 by ECAE and thermal treatments. Soft Nanosci Lett 2011; 1(4):120-129.

[21] Grante C, Andersson J. A method for evaluating functional content in mechatronic systems using optimisation. Res Eng Design 2003; 14:224-235.

[22] Burman A, Møster E, Abrahamsson P. On the influence of functional materials on engineering design. Res Eng Design 2000; 12:39-47.

[23] Salcedo D, Luis CJ, Puertas I, León J, Luri R, Fuertes JP. FEM modelling and experimental analysis of an AA5083 turbine blade from ECAE processed material. Mater Manuf Proc 2014; 29(4):434-441.

[24] ISO 6507-1:2005. Metallic materials. Vickers hardness test. Part 1: Test method.

[25] Agena SM. A study of flow characteristics of nanostructured Al-6082 alloy produced by ECAP under upsetting test. J Mater Process Technol 2009; 209:856863. 